ISSN: 2053-2296

journals.iucr.org/C

\title{
Single-crystal-to-single-crystal transformations triggered by dehydration in polyoxometalate-based compounds
}

\section{Santiago Reinoso, Beñat Artetxe and Juan M. Gutiérrez-Zorrilla}

Acta Cryst. (2018). C74, 1222-1242

\section{IUCr Journals CRYSTALLOGRAPHY JOURNALS ONLINE \\ Copyright (C) International Union of Crystallography \\ Author(s) of this paper may load this reprint on their own web site or institutional repository provided that this cover page is retained. Republication of this article or its storage in electronic databases other than as specified above is not permitted without prior permission in writing from the IUCr. \\ For further information see http://journals.iucr.org/services/authorrights.html}




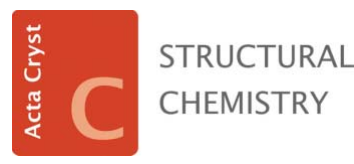

ISSN 2053-2296

Received 11 June 2018

Accepted 7 August 2018

Edited by J. R. Galán-Mascarós, Institute of Chemical Research of Catalonia (ICIQ), Spain

Keywords: polyoxometalate; POM; crystal-tocrystal transitions; dynamic behaviour; robust frameworks; crystal engineering.

Supporting information: this article has supporting information at journals.iucr.org/c

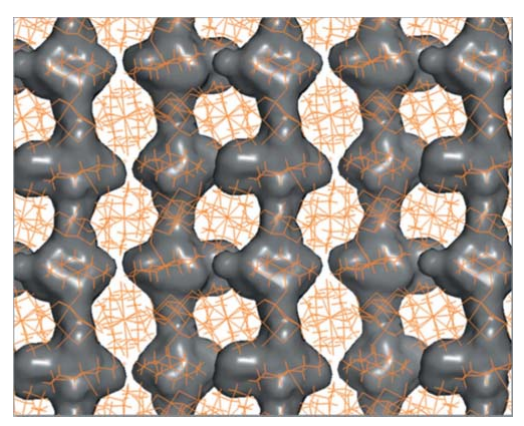

C 2018 International Union of Crystallography

\section{Single-crystal-to-single-crystal transformations triggered by dehydration in polyoxometalate-based compounds}

\author{
Santiago Reinoso, ${ }^{a *}$ Beñat Artetxe $^{\mathrm{b}}$ and Juan M. Gutiérrez-Zorrilla ${ }^{\mathrm{b}}$
}

anstitute for Advanced Materials (InaMat), Universidad Pública de Navarra (UPNA), Edificio Jerónimo de Ayanz, Campus de Arrosadia, Pamplona 31006, Spain, and ${ }^{\mathbf{b}}$ Departamento de Química Inorgánica, Facultad de Ciencia y Tecnología, Universidad del País Vasco UPV/EHU, PO Box 644, Bilbao 48080, Spain. *Correspondence e-mail:

santiago.reinoso@unavarra.es

Single-crystal-to-single-crystal transformations are solid-state phase transitions between different crystalline states in which the crystal integrity and the longrange structural order are retained through the whole transformation process. Such a phenomenon constitutes the structural response that some compounds afford when being exposed to a given external stimulus (temperature, pressure, light, etc.) and, therefore, its study has become a relevant focus of interest within crystal engineering because it allows for monitoring how certain properties (colour, magnetism, luminescence, porosity) of the stimuli-responsive material are modified as the structure evolves into the activated form. A range of organic, inorganic and hybrid systems have been found to undergo such phase transitions, but these examples only include a small number of compounds that incorporate polyoxometalate anions, among which the removal of guest solvent molecules (dehydration) stands out as the most common external stimulus able to induce the occurrence of a single-crystal-to-single-crystal transformation. This feature article compiles the examples of dehydrationtriggered single-crystal-to-single-crystal transformation studies that have been reported to date for polyoxometalate-based compounds and reviews some of their most relevant structural aspects.

\section{Introduction}

Solid-state phase transitions in which the long-range structural order and the single-crystal integrity are retained through the whole transformation process between the initial and final crystalline states represent a remarkable focus of attention within crystal engineering and materials science. Such a phenomenon, known as single-crystal-to-single-crystal (hereafter abbreviated as SCSC) transformation, constitutes the structural response that a given external stimulus, such as temperature, pressure or light, triggers when applied to certain crystalline solids, and it is usually accompanied by significant modifications to some of their physicochemical properties (e.g. colour, luminescence, magnetism, porosity). The occurrence of SCSC transformations allows for the unequivocal determination of the exact location of atoms and molecules within the crystal packing of the activated phase of the responsive material and, therefore, it offers an incomparable tool to correlate the modifications observed for the property of interest with the mechanism through which the structural transitions proceed (Halasz, 2010; Friššić \& MacGillivray, 2005; Hao \& Zhang, 2011; Coronado \& Mínguez Espallargas, 2013; Ke \& Wang, 2015). This information can prove crucial for fine-tuning the functionality of the material because it 
paves the way for modulating the changes in the physicochemical properties on demand by applying the principles of crystal engineering to the material to control the structural response to the triggering stimulus that gives rise to such changes. This fact endows crystalline solids capable of undergoing SCSC transformations with superior potentialities that might widen the scope of their applications as switches, memories, storage devices or sensors.

According to the type of structural behaviour upon application of the triggering stimulus, crystalline responsive materials can be roughly classified into three different groups: polymorphic compounds, dynamic materials and robust frameworks. The first group of materials encompasses those compounds for which different convertible polymorphic forms exist as a result of order-disorder transitions or atoms undergoing motions that break or change the crystal symmetry and lattice parameters. For the class of dynamic materials, SCSC transitions involve the cleavage and/or formation of covalent or coordination bonds, as well as extensive rearrangement of the network of intermolecular interactions that stabilize the crystal packing, which often results in remarkable changes of the overall structural architecture. In contrast, the architecture of the robust frameworks is essentially preserved intact throughout the SCSC transformation process, regardless of any compositional or functional variation promoted, for example, by the evacuation, incorporation or exchange of ions and guest molecules or by variations in the oxidation states of the constituent atoms.

The SCSC transformation phenomenon has been described in recent years for several different types of both purely organic (Centore et al., 2015; Takahashi \& Tamura, 2015; Hagihara et al., 2015; Mouchaham et al., 2015; Khorasani et al., 2015) and inorganic systems (Zakharov et al., 2015; Avdeeva et al., 2015), as well as for a vast number of coordination compounds based on the combination of metal-ion centres and organic ligands that includes metal-organic frameworks (MOFs) of covalent or supramolecular nature (Neogi et al., 2014; Ren et al., 2015; Manna et al., 2015; Lee et al., 2015) and porous coordination polymers (Li et al., 2015; Coronado et al., 2012; Tahier \& Oliver, 2015; Aromí et al., 2016) beyond simple

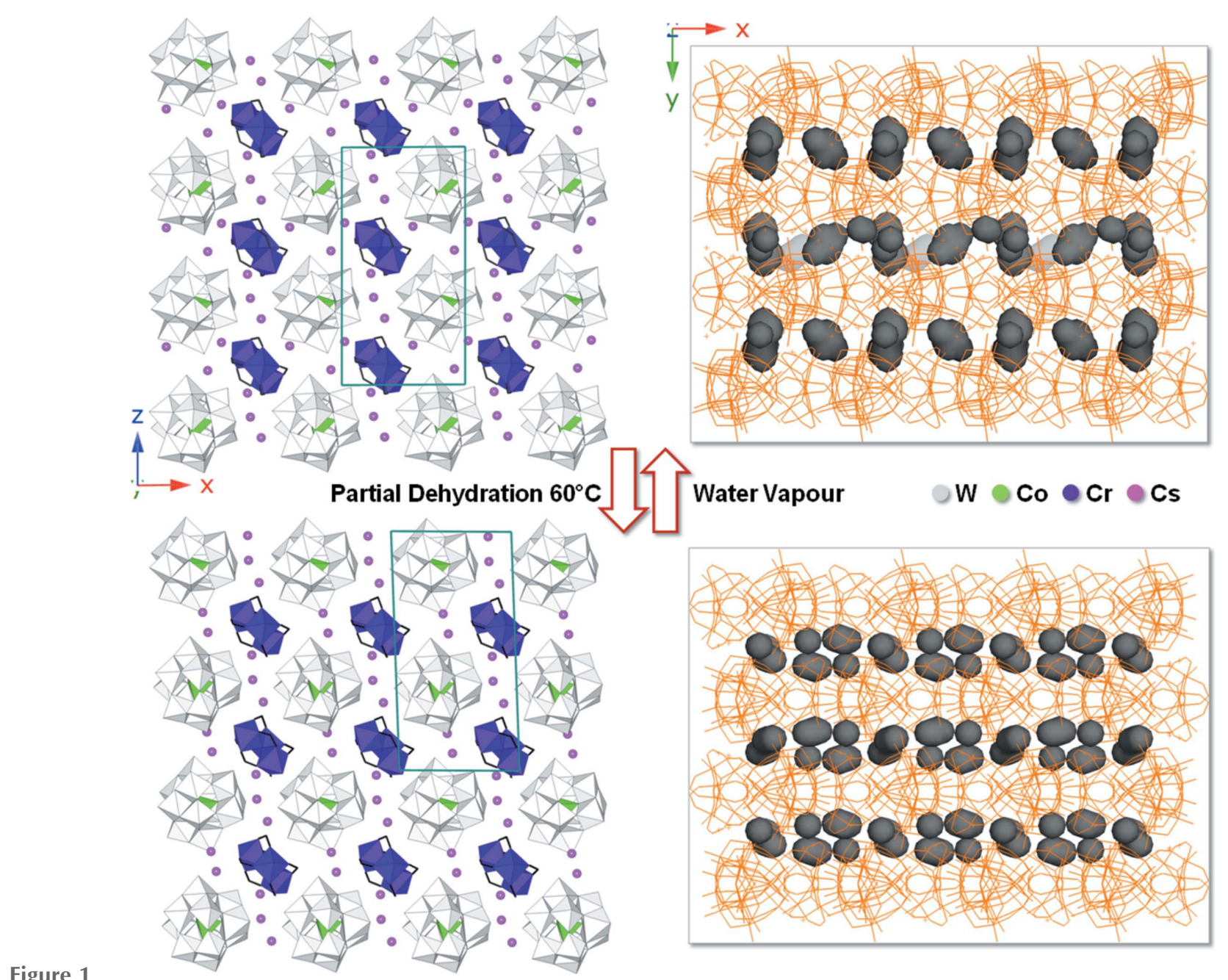

Figure 1

Comparison between hybrid layers in the crystallographic ac plane and solvent-accessible spaces viewed along the crystallographic $c$ axis for $\mathrm{Cs}_{5}\left[\mathrm{Cr}_{3} \mathrm{O}\left(\mathrm{O}_{2} \mathrm{CH}\right)_{6}\left(\mathrm{H}_{2} \mathrm{O}\right)_{3}\right]\left[\mathrm{CoW}_{12} \mathrm{O}_{40}\right] \cdot 7.5 \mathrm{H}_{2} \mathrm{O}$ and its partially dehydrated derivative $\mathrm{Cs}_{5}\left[\mathrm{Cr}_{3} \mathrm{O}\left(\mathrm{O}_{2} \mathrm{CH}\right)_{6}\left(\mathrm{H}_{2} \mathrm{O}\right)_{3}\right]\left[\mathrm{CoW}_{12} \mathrm{O}_{40}\right] \cdot 3.5 \mathrm{H}_{2} \mathrm{O}$. The $\mathrm{CIFs}$ deposited in the CSD for these compounds [refcodes ASOCAM and ASOCEQ (Uchida \& Mizuno, 2004; Uchida et al., 2006)] do not contain H atoms for the carboxylate ligands. 
coordination complexes. In contrast, literature reports on SCSC transitions involving compounds that incorporate polyoxometalate (POM) clusters are comparatively much less common (Reinoso et al., 2016), despite the fact that solid-state transformations have been known for decades in POM chemistry, as exemplified by the thermally-triggered isomerization of the trilacunary $\left[\mathrm{PW}_{9} \mathrm{O}_{34}\right]^{9-}$ Keggin-type cluster from the $\mathrm{A} \alpha$-form into the $\mathrm{B} \alpha$-derivative (Finke et al., 1987). To date, to our knowledge, only about 20 different types of POM-based compounds (some of them being families of compounds comprising several isostructural members) have been identified as being able to undergo an SCSC transformation.

The ring opening of the cyclic $\left[\mathrm{V}_{4} \mathrm{O}_{12}\right]^{4-}$ tetrametavanadate anion and subsequent polymerization into the catena- $\left[\mathrm{VO}_{3}\right]^{-}$ species (Wéry et al., 1996) represents the first example in POM chemistry of a solid-state phase transition for which the structures of the initial and final crystalline states were characterized by single-crystal X-ray diffraction. The transformation involved loss of the single-crystal integrity and resulted in a crystalline powder; single crystals of the catena form could be grown by recrystallization of this powder and the corresponding crystallographic characterization performed. Recent examples of POMs that undergo solid-state transformations for which the initial and final stages have been characterized by single-crystal X-ray diffraction in spite of the loss of the single-crystal integrity during the transition process include $\left[\left\{\mathrm{Zn}\left(\mathrm{OH}_{2}\right)(\mathrm{OH})\right\}_{2}\left\{\mathrm{Zn}\left(\mathrm{OH}_{2}\right)_{2}\right\}_{2}\left\{\gamma-\mathrm{HSiW}_{10} \mathrm{O}_{36}\right\}_{2}\right]^{8-}$ (Kikukawa et al., 2010a), the thermal treatment of which leads to two isomers of the $\left[\left\{\mathrm{Zn}_{2} \mathrm{~W}(\mathrm{O}) \mathrm{O}_{3}\right\}_{2} \mathrm{H}_{4}\left\{\mathrm{SiW}_{9} \mathrm{O}_{33}\right\}_{2}\right]^{8-}$ anion (Kikukawa et al., 2010b) through isomerization of the $\gamma$-subunits into $\alpha$ - or $\beta$-forms and consequent rearrangement of the planar $\left\{\mathrm{Zn}_{4}\right\}$ rhomb-like core into a $\left\{\mathrm{Zn}_{4} \mathrm{~W}_{2}\right\}$ hexaprismatic moiety, or $\left[\mathrm{Co}_{4}(\mathrm{OH})_{4}\left(\mathrm{H}_{4} \mathrm{SiW}_{10} \mathrm{O}_{36}\right)_{2}\right]^{8-}$ (Kuriyama et al., 2016), the cubane-type $\left\{\mathrm{Co}_{4}\right\}$ core of which transforms into a rhomblike moiety upon exposure to water resulting in the $\left[\left\{\mathrm{Co}\left(\mathrm{H}_{2} \mathrm{O}\right)\right\}_{2}(\mathrm{OH})_{2}\left\{\mathrm{Co}\left(\mathrm{H}_{2} \mathrm{O}\right)_{2}\right\}_{2}\left(\mathrm{H}_{2} \mathrm{SiW}_{10} \mathrm{O}_{36}\right)_{2}\right]^{8-}$ species. To our knowledge, the first SCSC transformation report on a POM-based compound that involved single-crystal X-ray diffraction measurements of the initial and final crystalline phases carried out on the same crystal before and after exposure to the external triggering stimulus was published as recently as 2004 and included comparative structural descriptions of the microporous ionic crystal $\mathrm{Cs}_{5}\left[\mathrm{Cr}_{3} \mathrm{O}\left(\mathrm{O}_{2} \mathrm{CH}\right)_{6}\right.$ $\left.\left(\mathrm{H}_{2} \mathrm{O}\right)_{3}\right]\left[\mathrm{CoW}_{12} \mathrm{O}_{40}\right] \cdot 7.5 \mathrm{H}_{2} \mathrm{O}$ and its partially dehydrated hemiheptahydrate derivative (Uchida \& Mizuno, 2004).

The scarcity of SCSC transformation studies associated with POM-based compounds that have been reported during the last decade is remarkable when compared to, for example, metal-organic frameworks (MOFs) and porous coordination polymers, but nevertheless, reports on POM-based SCSC transitions already include examples of polymorphism, dynamic behaviour and architectural robustness, and cover also a number of compositionally and/or structurally different systems that range from molecular clusters to three-dimensional covalent assemblies, or from purely inorganic compounds to organic salts and a relevant number of inor- ganic/metal-organic hybrid materials. With regard to the triggering stimuli, phase transitions promoted by the application of a number of different effects have been described.

(i) Temperature, as illustrated by the polymorphic transitions in $\left[\mathrm{C}\left(\mathrm{NH}_{2}\right)_{3}\right]_{6}\left[\mathrm{Mo}_{7} \mathrm{O}_{24}\right] \cdot \mathrm{H}_{2} \mathrm{O}$ from a room-temperature $C 2 / c$ monoclinic phase (Don \& Weakley, 1981) to a lowtemperature $P 2_{1} / c$ monoclinic phase at $173 \mathrm{~K}$ (Reinoso et al., 2008); $\left[\mathrm{Tm}_{2}\left(\mathrm{H}_{2} \mathrm{O}\right)_{14} \mathrm{CrMo}_{6} \mathrm{O}_{24} \mathrm{H}_{6}\right]\left[\mathrm{CrMo}_{6} \mathrm{O}_{24} \mathrm{H}_{6}\right] \cdot 16 \mathrm{H}_{2} \mathrm{O}$ from a room-temperature $P \overline{1}$ triclinic phase to a second $P \overline{1}$ phase at $113 \mathrm{~K}$ (Zhang et al., 2008a); and [Co(Hbpe $\left.)_{2}\left(\mathrm{~V}_{4} \mathrm{O}_{12}\right)\right]$ [bpe is 1,2-bis(pyridin-4-yl)ethane] from a room-temperature $P \overline{1}$ triclinic phase to a high-temperature $C \overline{1}$ triclinic intermediate at $438 \mathrm{~K}$ that evolves into a $C 2 / m$ monoclinic phase at $533 \mathrm{~K}$ (Fernández de Luis et al., 2011).

(ii) Light, as exemplified by the photo-polymerization of the ionic $\left[\mathrm{Gd}_{2}(\mathrm{NMP})_{12}\left(\mathrm{PW}_{12} \mathrm{O}_{40}\right)\right]\left[\mathrm{PW}_{12} \mathrm{O}_{40}\right]$ compound (NMP is $\mathrm{N}$-methyl-2-pyrrolidone) into the $\left[\mathrm{Gd}(\mathrm{NMP})_{6}\left(\mathrm{PW}_{12} \mathrm{O}_{40}\right)\right]$ onedimensional hybrid polymer (Zhang et al., 2008b).

(iii) Redox processes, as observed for a family of fully inorganic $\left[\mathrm{H}_{m} M_{12} X_{7} \mathrm{~W}_{72} \mathrm{O}_{268}\right]^{n-}$ three-dimensional covalent frameworks $(M=\mathrm{Mn}, \mathrm{Co} ; X=\mathrm{Si}, \mathrm{Ge})$ composed of first-row transition-metal-polysubstituted Keggin-type subunits in which the manganese and cobalt centres can be reversibly switched between the +2 and +3 oxidation states with full retention of the framework architecture (Ritchie et al., 2008; Thiel et al., 2009, 2010).

(iv) Post-synthetic modifications, including the proton/ transition-metal cation exchange that transforms the manganese(II)-linked one-dimensional assemblies of sandwich-type POMs in $\left(\mathrm{H}_{3} \mathrm{O}\right)_{4}\left[\mathrm{Mn}_{4}\left(\mathrm{H}_{2} \mathrm{O}\right)_{18}\right]\left[\mathrm{WZnMn}_{2}\left(\mathrm{H}_{2} \mathrm{O}\right)_{2}\left(\mathrm{ZnW}_{9} \mathrm{O}_{34}\right)_{2}\right] \cdot-$ $18 \mathrm{H}_{2} \mathrm{O}$ into the covalent three-dimensional framework of $\left[M_{2}\left(\mathrm{H}_{2} \mathrm{O}\right)_{6}\right]\left[\mathrm{Mn}_{4}\left(\mathrm{H}_{2} \mathrm{O}\right)_{16}\right]\left[\mathrm{WZnMn}_{2}\left(\mathrm{H}_{2} \mathrm{O}\right)_{2}\left(\mathrm{ZnW}_{9} \mathrm{O}_{34}\right)_{2}\right] \cdot 10 \mathrm{H}_{2} \mathrm{O}$ $\left(M=\mathrm{Co}^{2+}, \mathrm{Cu}^{2+}\right.$; Shi et al., 2011); the dissociative incorporation of water that transforms (TBA) ${ }_{4}\left[\mathrm{SiV}_{2} \mathrm{~W}_{10} \mathrm{O}_{39}\right] \cdot 2 \mathrm{DCE}$ (TBA is tetra- $n$-butylammonium and DCE is 1,2-dichloroethane) with a $\mu$-oxido-divanadium core into (TBA) $)_{4}[\mathrm{Si}$ $\left.\mathrm{V}_{2} \mathrm{~W}_{10} \mathrm{O}_{38}(\mathrm{OH})_{2}\right] \cdot 2 \mathrm{DCE}$, showing a di- $\mu$-hydroxido-divanadium moiety (Uehara \& Mizuno, 2011); and the concomitant ligand/cation exchange induced by protonation that converts $\mathrm{K}_{2}\left[\mathrm{Cr}_{3} \mathrm{O}\left(\mathrm{O}_{2} \mathrm{CH}\right)_{6}(\text { etpy })_{3}\right]_{2}\left[\mathrm{SiW}_{12} \mathrm{O}_{40}\right] \cdot 8 \mathrm{H}_{2} \mathrm{O}$ (etpy is 4-ethylpyridine; Eguchi et al., 2012) and $\mathrm{K}_{2}\left[\mathrm{Cr}_{3} \mathrm{O}\left(\mathrm{O}_{2} \mathrm{CH}\right)_{6}(\mathrm{me}-\right.$ py $\left.)_{3}\right]_{2}\left[\mathrm{SiW}_{12} \mathrm{O}_{40}\right] \cdot 8 \mathrm{H}_{2} \mathrm{O}$ (mepy is 4-methylpyridine; Uchida et $a l ., 2010)$ into the $(\text { etpyH })_{2}\left[\mathrm{Cr}_{3} \mathrm{O}\left(\mathrm{O}_{2} \mathrm{CH}\right)_{6}(\text { etpy })_{2}\left(\mathrm{H}_{2} \mathrm{O}\right)\right]_{2}[\mathrm{Si}$ $\left.\mathrm{W}_{12} \mathrm{O}_{40}\right] \cdot 6 \mathrm{H}_{2} \mathrm{O}$ (Uchida et al., 2013b) and $\mathrm{K}(\mathrm{mepyH})\left[\mathrm{Cr}_{3} \mathrm{O}-\right.$ $\left.\left(\mathrm{O}_{2} \mathrm{CH}\right)_{6}(\text { mepy })_{2}\left(\mathrm{H}_{2} \mathrm{O}\right)\right]_{2}\left[\mathrm{SiW}_{12} \mathrm{O}_{40}\right] \cdot 7 \mathrm{H}_{2} \mathrm{O}$ (Uchida et al., 2014) derivatives, respectively, but with overall retention of the microporous ionic framework.

However, it is the removal of guest solvent molecules, and more specifically the evacuation of water molecules of both coordination and solvation, which is the effect that stands out as the most common external stimulus able to induce the occurrence of the SCSC transformation phenomenon in compounds that incorporate POM clusters. The examples of SCSC transformation studies triggered by dehydration that have been reported to date for POM-based systems are compiled below and some of their most relevant structural aspects are reviewed. 


\section{Structural robustness towards dehydration in polyoxometalate-based frameworks}

2.1. Porous ionic crystals based on $\left[M^{\prime \prime \prime \prime}{ }_{3} \mathrm{O}\left(\mathrm{O}_{2} \mathrm{CR}\right)_{6}(L)_{3}\right]^{+}$ macrocations and Keggin-type anions

A massive collection of microporous crystalline solids composed of $\alpha$-Keggin-type POM anions and triangular $\left[M^{\mathrm{IIII}}{ }_{3} \mathrm{O}\left(\mathrm{O}_{2} \mathrm{CR}\right)_{6}(L)_{3}\right]^{+}$macrocations, in which the trivalent transition metals $\left(M^{\mathrm{III}}=\mathrm{Cr}, \mathrm{Fe}\right)$ are linked by a central $\mu_{3^{-}}$ oxido and six peripheral $\mu_{2}-\left(\kappa^{2} O: O^{\prime}\right)$-carboxylate ligands and show one terminal ligand each $\left(L=\mathrm{H}_{2} \mathrm{O}\right.$, pyridines, etc. $)$, has been reported in recent years (Uchida \& Mizuno, 2007; Mizuno et al., 2009). The complementary topologies of anions and cations lead to the formation of ionic open-framework architectures that show solvent-accessible voids and/or channels, and according to powder X-ray diffraction studies, the latter can be evacuated without collapse of the micropores and with retention of the crystallinity in most cases (Uchida et al., 2005, 2012, 2013a; Tagami et al., 2009; Kawahara et al., 2014). However, the structure of the resulting guest-free activated phase has been determined by single-crystal X-ray diffraction only for a very few cases. The pair formed by $\mathrm{Cs}_{5}\left[\mathrm{Cr}_{3} \mathrm{O}\right.$ $\left.\left(\mathrm{O}_{2} \mathrm{CH}\right)_{6}\left(\mathrm{H}_{2} \mathrm{O}\right)_{3}\right]\left[\mathrm{CoW}_{12} \mathrm{O}_{40}\right] \cdot 7.5 \mathrm{H}_{2} \mathrm{O}$ and its partially dehydrated derivative $\mathrm{Cs}_{5}\left[\mathrm{Cr}_{3} \mathrm{O}\left(\mathrm{O}_{2} \mathrm{CH}\right)_{6}\left(\mathrm{H}_{2} \mathrm{O}\right)_{3}\right]\left[\mathrm{CoW}_{12} \mathrm{O}_{40}\right] \cdot 3.5 \mathrm{H}_{2} \mathrm{O}$ are one amongst these scarce examples and, as mentioned above, they represent the first SCSC transformation study associated with a POM-based compound in the literature (Uchida \& Mizuno, 2004; Uchida et al., 2006).

The parent compound crystallizes in the monoclinic space group $P 2_{1} / c$ and the asymmetric unit contains one $\left[\mathrm{CoW}_{12} \mathrm{O}_{40}\right]^{6-}$ anion, one $\left[\mathrm{Cr}_{3} \mathrm{O}\left(\mathrm{O}_{2} \mathrm{CH}\right)_{6}\left(\mathrm{H}_{2} \mathrm{O}\right)_{3}\right]^{+}$complex cation, five $\mathrm{Cs}^{+}$cations (one of which is disordered over two crystallographically independent sites) and 7.5 water molecules of hydration. The Keggin-type anions and the complex macrocations are hydrogen bonded in rows along the [201] direction through $\mathrm{O}_{\mathrm{w}}-\mathrm{H} \cdots \mathrm{O}_{\mathrm{POM}}$ interactions that involve the aqua ligands, and these rows are arranged in layers parallel to the crystallographic ac plane through $\mathrm{C}-\mathrm{H} \cdots \mathrm{O}_{\mathrm{POM}}$ contacts (Fig. 1). The stacking of these hybrid layers along the [010] direction is such that solvent-accessible spaces toward which the $\mathrm{Cs}^{+}$ions are directed are formed in the interlamellar space. This space accounts for $17 \%$ of the unit-cell volume and hosts all of the 7.5 water molecules of hydration per POM cluster, which are hydrogen bonded in winding chains that were claimed to reside in channels parallel to the crystallographic $a$ axis in the original report. However, the representation of the solvent-accessible space displayed in Fig. 1 shows that such channels are in fact disrupted and, therefore, should be better described as a succession of cavities communicated through narrow necks occupied by the $\mathrm{Cs}^{+}$ ions.

The parent compound undergoes loss of four water molecules per cluster at mild temperatures resulting in the partially dehydrated derivative with retention of the singlecrystal integrity and, as such, the structure of the latter could be determined from a single crystal of the parent compound kept at $60{ }^{\circ} \mathrm{C}$ under a flow of dry $\mathrm{N}_{2}$ for $3 \mathrm{~h}$. The unit-cell parameters were essentially maintained upon partial evacuation of water molecules, apart from a shortening of the $b$ dimension from 19.337 (5) to 18.641 (2) $\AA$ that led to a decrease of the unit-cell volume by $c a 5.5 \%$. The relative arrangement of the POM anions and macrocations in the hybrid layers parallel to the crystallographic $a c$ plane was virtually preserved (Fig. 1), but their stacking along the [010] direction became significantly more compact, in good agreement with the shortening of the $b$ parameter, and hence the solvent-accessible interlamellar space was nearly collapsed. This process proved to be fully reversible and the original structure could be restored upon exposure of the partially dehydrated phase to saturated water vapour, as demonstrated through powder X-ray diffraction monitoring. The uptake of water molecules proceeded via a type I isotherm characteristic of guest sorption into micropores and proved to be shapeselective over larger polar molecules (i.e. short-chain alcohols), allowing for the partially dehydrated crystal phase to be successfully used as desiccant of alcohol/water azeotropic mixtures to reach concentrations of water in the limits of those of anhydrous solvents.

$\mathrm{K}_{2}\left[\mathrm{Cr}_{3} \mathrm{O}\left(\mathrm{O}_{2} \mathrm{CC}_{2} \mathrm{H}_{5}\right)_{6}\left(\mathrm{H}_{2} \mathrm{O}\right)_{3}\right]_{2}\left[\mathrm{SiW}_{12} \mathrm{O}_{40}\right] \cdot 3 \mathrm{H}_{2} \mathrm{O}$ (Kawamoto et al., 2005) and $\mathrm{Rb}_{2}\left[\mathrm{Cr}_{3} \mathrm{O}\left(\mathrm{O}_{2} \mathrm{CC}_{2} \mathrm{H}_{5}\right)_{6}\left(\mathrm{H}_{2} \mathrm{O}\right)_{3}\right]_{2}[\mathrm{Si}-$ $\left.\mathrm{W}_{12} \mathrm{O}_{40}\right] \cdot 4 \mathrm{H}_{2} \mathrm{O}$ (Lesbani et al., 2008) are additional examples of microporous ionic crystalline materials based on $\alpha$-Keggintype POM cluster anions and triangular $\left[M^{\mathrm{III}}{ }_{3} \mathrm{O}\left(\mathrm{O}_{2} \mathrm{CR}\right)_{6}(L)_{3}\right]^{+}$ complex macrocations that undergo dehydration through SCSC transformation processes throughout which the framework architectures are essentially preserved. In both cases, the structures of the corresponding anhydrous phases obtained upon full evacuation of the guest water molecules, namely $\mathrm{K}_{2}\left[\mathrm{Cr}_{3} \mathrm{O}\left(\mathrm{O}_{2} \mathrm{CC}_{2} \mathrm{H}_{5}\right)_{6}\left(\mathrm{H}_{2} \mathrm{O}\right)_{3}\right]_{2}\left[\mathrm{SiW}_{12} \mathrm{O}_{40}\right]$ and $\mathrm{Rb}_{2}\left[\mathrm{Cr}_{3} \mathrm{O}\left(\mathrm{O}_{2} \mathrm{C}-\right.\right.$ $\left.\left.\mathrm{C}_{2} \mathrm{H}_{5}\right)_{6}\left(\mathrm{H}_{2} \mathrm{O}\right)_{3}\right]_{2}\left[\mathrm{SiW}_{12} \mathrm{O}_{40}\right]$, have been determined by singlecrystal X-ray diffraction studies performed on crystals of the parent compounds exposed to a flow of dry gas.

The parent compounds both crystallize in the monoclinic space group $C 2 / c$ with nearly identical unit-cell parameters, resulting in a slight difference of just $1.6 \%$ in the unit-cell volumes. The asymmetric units contain one half of a $\left[\mathrm{SiW}_{12} \mathrm{O}_{40}\right]^{4-}$ anion, one $\left[\mathrm{Cr}_{3} \mathrm{O}\left(\mathrm{O}_{2} \mathrm{CC}_{2} \mathrm{H}_{5}\right)_{6}\left(\mathrm{H}_{2} \mathrm{O}\right)_{3}\right]^{+}$complex cation, one alkali cation and a variable number of sites suitable for lattice water molecules. As for the Cs-containing microporous ionic framework commented on above, both compounds also display an intrinsic layered nature, but with the complex macrocations hydrogen bonded in zigzag rows along the [100] direction through $\mathrm{O}_{\mathrm{w}}-\mathrm{H} \cdots \mathrm{O}_{\mathrm{w}}$ interactions that involve the terminal aqua ligands. These rows are arranged in the crystallographic ac plane in a honeycomb pattern in which the POM clusters occupy the centre of the hexagonal tiles and establish a set of $\mathrm{O}_{\mathrm{w}}-\mathrm{H} \cdots \mathrm{O}_{\mathrm{POM}}$ hydrogen bonds with the aqua ligands of the six neighbouring macrocations (Figs. 2 and 3). The alkali cations and all of the water molecules of hydration are hosted in hydrophilic intralamellar pockets generated at the junctions of the metalorganic rows. The honeycomb-like hybrid layers stack along the crystallographic $b$ axis with macrocations from adjacent layers facing each other, which leads to the formation of 
hydrophobic regions in the interlamellar space toward which the aliphatic chains of the propionate ligands are directed. These hydrophobic regions have been defined as channels parallel to the crystallographic $a$ axis, with cross sections of $c a$ $3.8 \times 8.0$ and $3.6 \times 7.8 \AA$ (shortest internuclear $\mathrm{C} \cdots \mathrm{C}$ distances) for the $\mathrm{K}$ - and $\mathrm{Rb}$-containing salts, respectively, but the representation of the accessible void space shows that such channels are in fact disrupted and should be better described as a succession of hydrophobic cavities communicated through narrow windows (Figs. 2 and 3). The intralamellar pockets of adjacent layers are connected along the [110] direction through narrow necks hosting alkali cations, which results in the stacking of layers being diagonally intersected by hydrophilic channels.

Both compounds undergo desorption of all of the water molecules of hydration upon exposure to a flow of dry $\mathrm{N}_{2}$, which allowed the structures of the corresponding anhydrous phases to be determined by single-crystal X-ray diffraction experiments performed on crystals of the parent compounds kept at $30{ }^{\circ} \mathrm{C}$ during the intensity data collection. The unit-cell symmetry and dimensions were virtually unmodified upon water desorption, apert from a lengthening of the $c$ parameter from 30.169 (2) to 30.8544 (11) $\AA$ in the case of the Kcontaining salt and, hence, the relative arrangement of POM anions and complex macrocations in the hybrid layers parallel to the crystallographic ac plane, as well as their stacking along the [010] direction, was maintained without any relevant alteration upon dehydration. It is worth noting, however, that the accessible void space in the hydrophobic cavities of the Kcontaining anhydrous salt shrinks significantly compared to that found in the parent compound due to rearrangement of the flexible aliphatic chains of the carboxylate ligands, whereas that in the Rb-containing salt undergoes a slight increase when going from the parent compound to the anhydrous derivative.

The evacuation of guest water molecules and the consequent SCSC transformation proved to be reversible and the original structures could be fully restored upon exposure of the anhydrous forms to saturated water vapour, as evidenced through powder X-ray diffraction monitoring. Water molecules were demonstrated to be incorporated into the intralamellar hydrophilic pockets on the basis of the extent of water sorption at high pressures, which accounted for four molecules per formula unit and was nearly equal to the volume calculated for the hydrophilic channels, and the
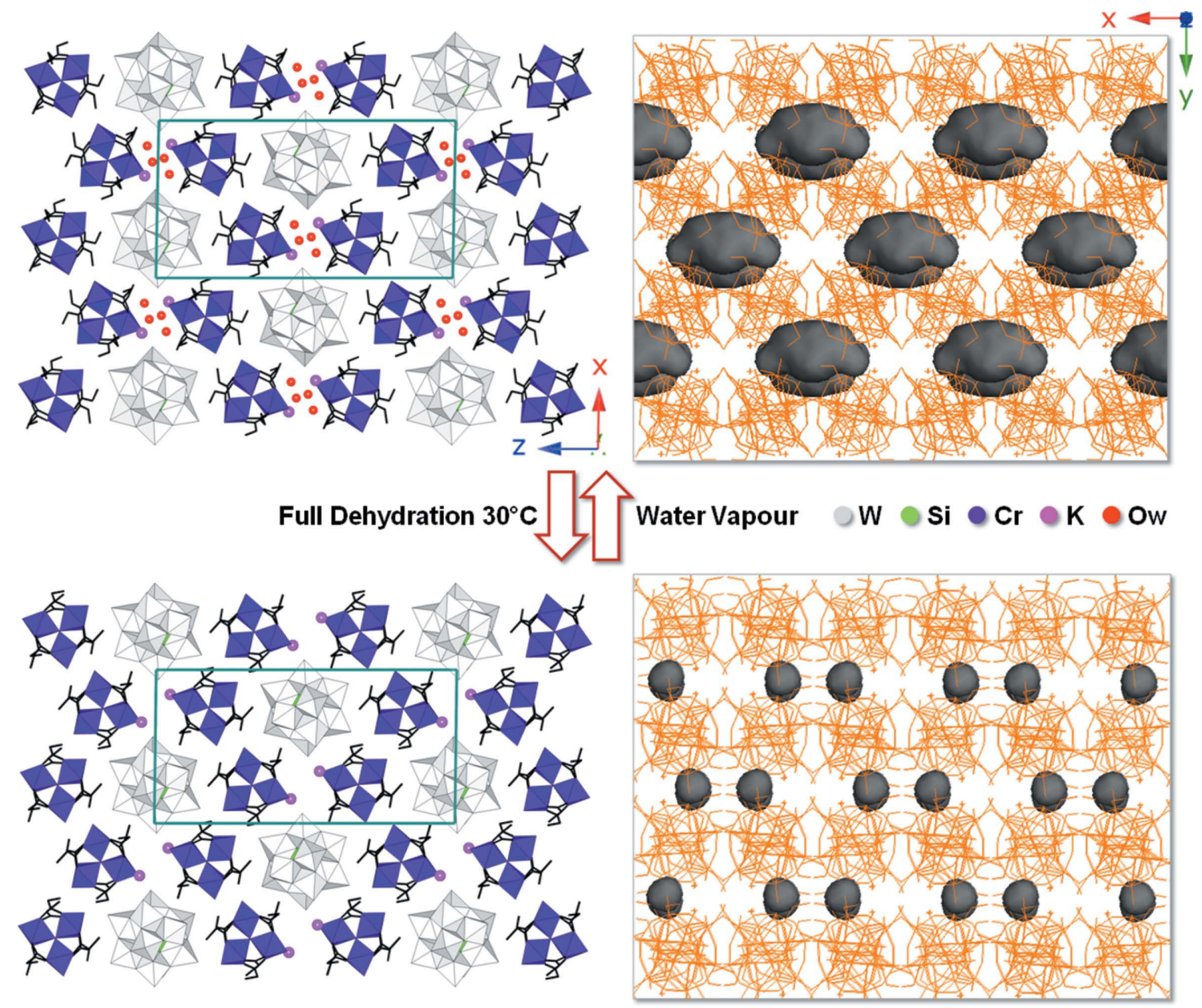

Figure 2

Comparison between hybrid layers in the crystallographic ac plane and accessible void spaces viewed along the crystallographic $c$ axis for $\mathrm{K}_{2}\left[\mathrm{Cr}_{3} \mathrm{O}\left(\mathrm{O}_{2} \mathrm{CC}_{2} \mathrm{H}_{5}\right)_{6}\left(\mathrm{H}_{2} \mathrm{O}\right)_{3}\right]_{2}\left[\mathrm{SiW}_{12} \mathrm{O}_{40}\right] \cdot 3 \mathrm{H}_{2} \mathrm{O}$ and its anhydrous form $\mathrm{K}_{2}\left[\mathrm{Cr}_{3} \mathrm{O}\left(\mathrm{O}_{2} \mathrm{CC}_{2} \mathrm{H}_{5}\right)_{6}\left(\mathrm{H}_{2} \mathrm{O}\right)_{3}\right]_{2}\left[\mathrm{SiW}_{12} \mathrm{O}_{40}\right]$. The CIFs deposited in the CSD for these compounds [refcodes KASFEQ and KATNEZ01 (Kawamoto et al., 2005; Lesbani et al., 2008)] do not contain $\mathrm{H}$ atoms for the carboxylate ligands. 
kinetics of the sorption process, which could be reproduced by a linear model with a single rate constant. Due to the coexistence of hydrophilic and hydrophobic accessible void spaces in the crystal packings of both $\mathrm{K}$ - and $\mathrm{Rb}$-containing compounds, the guest-free activated phases show amphiphilic sorption properties that depend on the molecular size, dipole moment and hydrogen-bonding ability of the incorporated guest. These phases adsorb polar organic molecules with a hydrogen-bonding ability (e.g. short-chain alcohols, nitriles), but exclude other polar species, as well as nonpolar molecules, regardless of the size (e.g. $\mathrm{CH}_{4}$, chlorocarbons). At high relative pressures, short-chain alcohols (ethanol, $n$-propanol) are incorporated into both types of accessible voids, with a preference for the interlamellar hydrophobic spaces, as inferred from the facts that: (i) IR spectroscopic data afford two $v(\mathrm{OH})$ signals originating from hydrogen-bonding (hydrophilic region) and non-interacting (hydrophobic region) species with relative intensities in good correlation with those of the two signals observed in the ${ }^{13} \mathrm{C}$ NMR spectra; (ii) the adsorption kinetics follow a model with two rate constants corresponding to two different processes; (iii) the amount of adsorbed guest molecules exceeds the volumes calculated for both types of void spaces separately. At low relative pressures, alcohol sorption into the hydrophilic pockets becomes dominant according to single-crystal X-ray diffraction experiments, which revealed the presence of one ethanol molecule coordinated to an alkali ion for the K-containing salt.

\subsection{A two-dimensional polyoxometalate/metal-organic} hybrid framework with POMOF-like behaviour

The microporous $[\mathrm{Cu}($ cyclam $)]\left[\{\mathrm{Cu}(\text { cyclam })\}_{2}\left(\mathrm{~V}_{10} \mathrm{O}_{28}\right)\right] \cdot 10 \mathrm{H}_{2} \mathrm{O}$ supramolecular framework (cyclam is 1,4,8,11-tetraazacyclotetradecane) has been recently described as displaying structural and functional features that closely resemble those of classical MOFs (Martín-Caballero et al., 2016). This representative example of the so-called hybrid POMOF-like compounds displays accessible channels filled with guest water molecules that can be thermally evacuated through an SCSC transition process, which has allowed for a full single-crystal $\mathrm{X}$-ray diffraction characterization of the activated $[\mathrm{Cu}$ (cyclam) $]\left[\{\mathrm{Cu}(\text { cyclam })\}_{2}\left(\mathrm{~V}_{10} \mathrm{O}_{28}\right)\right]$ anhydrous phase to be obtained.
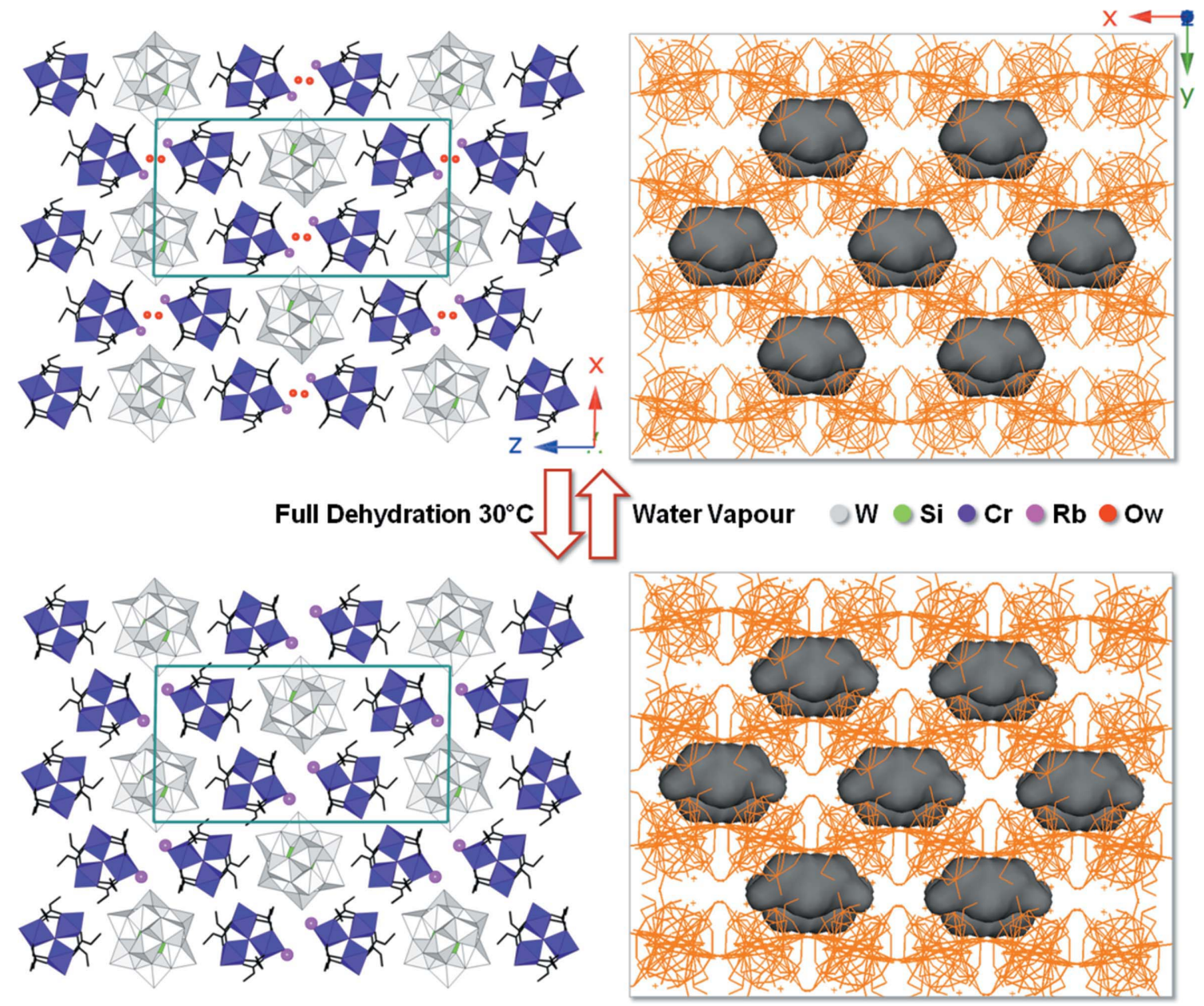

Figure 3

Comparison between hybrid layers in the crystallographic $a c$ plane and accessible void spaces viewed along the crystallographic $c$ axis for $\mathrm{Rb}_{2}\left[\mathrm{Cr}_{3} \mathrm{O}\left(\mathrm{O}_{2} \mathrm{CC}_{2} \mathrm{H}_{5}\right)_{6}\left(\mathrm{H}_{2} \mathrm{O}\right)_{3}\right]_{2}\left[\mathrm{SiW}_{12} \mathrm{O}_{40}\right] \cdot 4 \mathrm{H}_{2} \mathrm{O}$ and its anhydrous form $\mathrm{Rb}_{2}\left[\mathrm{Cr}_{3} \mathrm{O}\left(\mathrm{O}_{2} \mathrm{CC}_{2} \mathrm{H}_{5}\right)_{6}\left(\mathrm{H}_{2} \mathrm{O}\right)_{3}\right]_{2}\left[\mathrm{SiW}_{12} \mathrm{O}_{40}\right]$. The CIFs deposited in the CSD for these compounds (refcodes IROBAT and IROBUN; Lesbani et al., 2008) do not contain $\mathrm{H}$ atoms for the carboxylate ligands. 
The parent compound crystallizes in the triclinic space group $P \overline{1}$ with one half of a $\left[\mathrm{V}_{10} \mathrm{O}_{28}\right]^{6-}$ cluster, three crystallographically independent $\{\mathrm{Cu}(\text { cyclam })\}^{2+}$ moieties located on centres of inversion and five water molecules of hydration disordered over ten sites in the asymmetric unit. The structural role of two of the three independent $\{\mathrm{Cu}(\text { cyclam })\}^{2+}$ moieties is to act as linkers between clusters, whereas the third constitutes a charge-compensating complex cation. The $\mathrm{Cu}^{\mathrm{II}}$ atoms in the linkers show an elongated octahedral geometry, with the $\mathrm{N}_{4}$-donor cyclam ligand in a trans-III configuration forming the equatorial plane and the axial positions occupied by $\mathrm{O}_{\mathrm{POM}}$ atoms. In contrast, the charge-compensating subunit is a square-planar complex in which the $\mathrm{Cu}^{\mathrm{II}}$ centre does not display any axial ligand. The crystal packing displays an intrinsic layered nature as it contains two-dimensional covalent assemblies parallel to the crystallographic $b c$ plane in which the metal-organic linkers connect the POM clusters in the [001] and [010] directions following a square-like grid pattern. These covalent hybrid layers stack along the crystal- lographic $a$ axis with the grid voids superimposed on each other, and hence square-shaped channels with a cross-section of ca $10.4 \times 8.8 \AA$ (shortest internuclear distances between opposite $\mathrm{N}$ atoms) are formed (Fig. 4). The solvent-accessible volume in this system of individual channels parallel to the [100] direction is $428 \AA^{3}$, which accounts for nearly $25 \%$ of the unit-cell volume and hosts all of the water molecules of hydration without forming any remarkable network of hydrogen-bonding interactions. The charge-compensating subunits are sandwiched between decavanadate clusters of adjacent layers and act as effective cementing agents to reinforce the stacking of hybrid covalent lattices into a robust supramolecular open framework through a massive number of $\mathrm{N}-\mathrm{H} \cdots \mathrm{O}_{\mathrm{POM}}$ and $\mathrm{C}-\mathrm{H} \cdots \mathrm{O}_{\mathrm{POM}}$ interactions with the cluster surfaces.

With regard to the thermostructural behaviour of the title compound of this section, thermogravimetric analysis showed that dehydration extends from room temperature to $c a 100{ }^{\circ} \mathrm{C}$ and results in an anhydrous phase with a wide range of
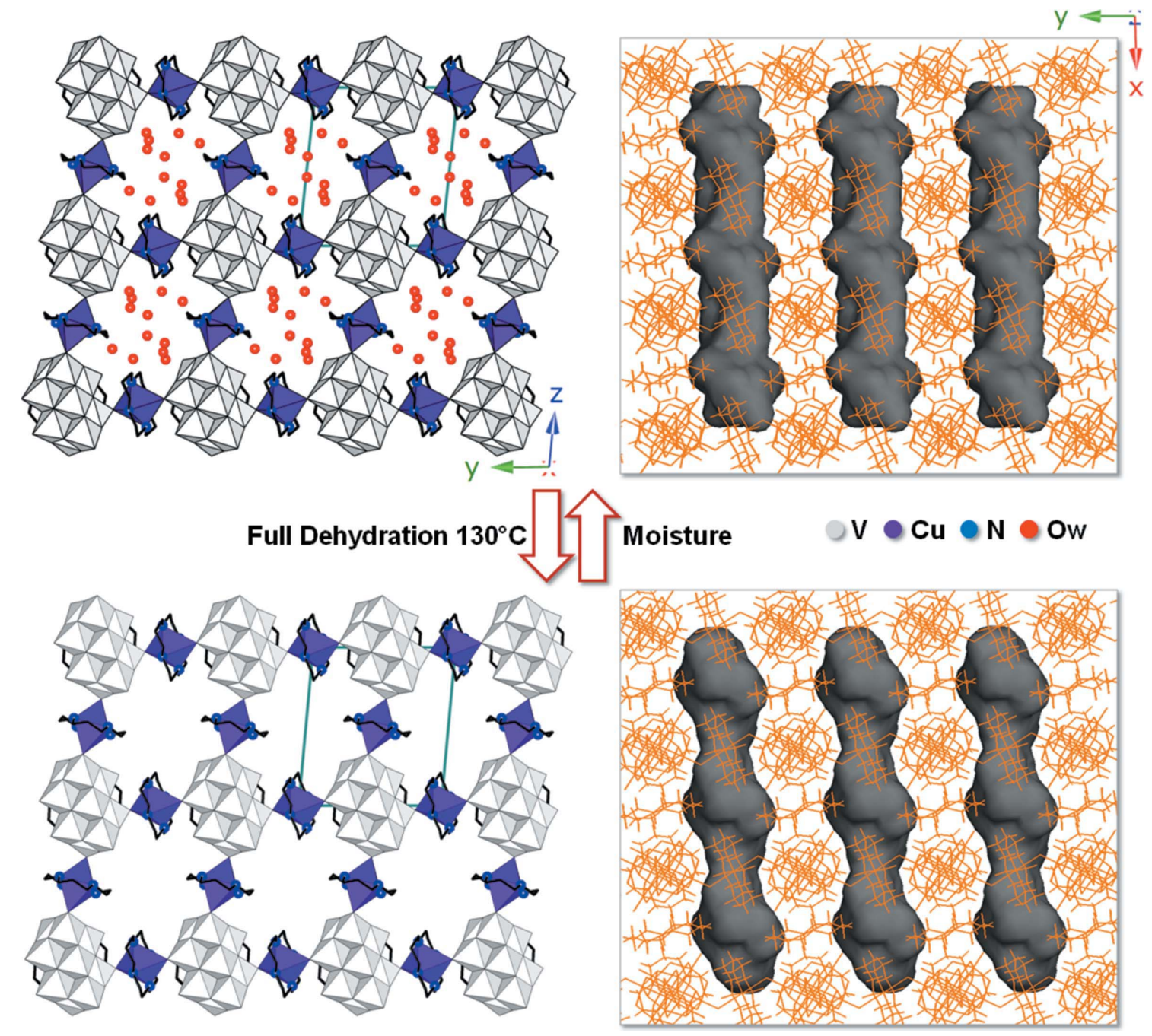

Figure 4

Comparison between the crystal packings viewed along the crystallographic $a$ axis ( $\mathrm{H}$ atoms have been omitted for clarity) and solvent-accessible spaces viewed along the crystallographic $c$ axis for $[\mathrm{Cu}($ cyclam $)]\left[\{\mathrm{Cu}(\text { cyclam })\}_{2}\left(\mathrm{~V}_{10} \mathrm{O}_{28}\right)\right] \cdot 10 \mathrm{H}_{2} \mathrm{O}$ and its $[\mathrm{Cu}($ cyclam $)]\left[\{\mathrm{Cu}(\mathrm{cyclam})\}_{2}\left(\mathrm{~V}_{10} \mathrm{O}_{28}\right)\right]$ anhydrous form. 
thermal stability up to a temperature of around $160{ }^{\circ} \mathrm{C}$. Variable-temperature powder X-ray diffraction studies revealed, in turn, that crystallinity is retained throughout the whole dehydration process and subsequent range of thermal stability, with the diffraction pattern remaining virtually unaltered but for some subtle variations in the $90-100{ }^{\circ} \mathrm{C}$ range, which corresponds to the temperature at which dehydration is completed and the resulting anhydrous phase is formed. This fact evidenced that the unit-cell parameters of the parent compound are essentially preserved in the anhydrous derivative without any substantial variations. Thanks to dehydration proceeding without loss of crystal integrity, the structure of the anhydrous phase could be determined from single-crystal X-ray diffraction measurements performed at $-173{ }^{\circ} \mathrm{C}$ on a crystal of the parent compound that had been heated to $130{ }^{\circ} \mathrm{C}$ to evacuate all of the guest water molecules. These experiments confirmed that the square-like grid pattern of POM anions and metal-organic linkers in the covalent hybrid layers parallel to the crystallographic $b c$ plane, as well as their stacking cemented along the [100] direction by the charge-compensating subunits, is maintained without any significant alteration upon dehydration, in such a way that the guest-free channels in the anhydrous phase were found to be nearly identical to those of the parent compound, apart from a decrease of just $30 \AA^{3}$ in the solvent-accessible volume produced by a subtle rotation of metal-organic linkers around their axial axes and a consequent slight channel narrowing when intersecting the layers (Fig. 4). Thus, singlecrystal X-ray crystallography established the permanent porosity of the supramolecular framework, which rendered functionality to the title compound of the section in the selective adsorption of small gas molecules $\left(\mathrm{CO}_{2}\right.$ over $\left.\mathrm{N}_{2}\right)$ and as heterogeneous catalyst toward the $\mathrm{C}-\mathrm{H}$ bond activation of cycloalkanes with hydrogen peroxide. With regard to the first aspect, the adsorption of $\mathrm{CO}_{2}$ followed a type I isotherm characteristic of microporous materials, and the calculated BET (Brunauer-Emmett-Teller) surface area $\left(205 \mathrm{~m}^{2} \mathrm{~g}^{-1}\right)$ was significantly larger than most of the POM-based microporous supramolecular ionic frameworks known to date, among which some remarkable examples have been discussed in $\$ 2.1$.

\subsection{When solvent molecules are just fillers}

An additional example of a hybrid framework based on POM clusters and $\{\mathrm{Cu}(\text { cyclam })\}^{2+}$ metal-organic moieties showing robustness towards dehydration has been reported recently, namely $\left[\{\mathrm{Cu}(\text { cyclam })\}_{2}\left(\mathrm{Mo}_{8} \mathrm{O}_{26}\right)\right] \cdot 1.5 \mathrm{H}_{2} \mathrm{O}$ (Dissem et $a l ., 2018)$. The dehydration process into the $\left[\{\mathrm{Cu}(\text { cyclam })\}_{2}-\right.$ $\left(\mathrm{Mo}_{8} \mathrm{O}_{26}\right)$ ] anhydrous phase does not proceed through an SCSC transformation in a strict sense, but through an SC-tocrystal transition, as the release of hydration water molecules from the parent compound has been found to result in nonmerohedral twinning and, hence, the single-crystal integrity is lost through the process. Nevertheless, we have decided to include this example in this article because the structure of the anhydrous phase could be easily determined from single- crystal X-ray diffraction data by applying a simple twocomponent twin model during the data reduction to exclude the reflections of the minor component $(22 \%$ of the reflections).

The parent compound crystallizes in the triclinic space group $P \overline{1}$, with one half of a $\gamma-\left\{\mathrm{Mo}_{8} \mathrm{O}_{26}\right\}^{4-}$ subunit, two crystallographically independent $\{\mathrm{Cu}(\text { cyclam })\}^{2+}$ moieties located on centres of inversion and one site suitable for a water molecule of hydration, with a population factor of 0.75 , in the asymmetric unit. The POM fragment belongs to a onedimensional polymeric assembly in which contiguous octamolybdate subunits are covalently linked in a head-to-tail fashion via two Mo-O-Mo bridges between corner-sharing $\left\{\mathrm{MoO}_{6}\right\}$ octahedra. The two independent $\{\mathrm{Cu}(\text { cyclam })\}^{2+}$ moieties display an elongated octahedral geometry with the $\mathrm{N}_{4}$-donor cyclam ligand in a trans-III configuration forming the equatorial plane and the axial positions occupied by $\mathrm{O}_{\mathrm{POM}}$ atoms and, therefore, both act as linkers between polymeric POM assemblies. The crystal packing thus consists of a threedimensional covalent framework formed by $\left\{\left[\gamma-\mathrm{Mo}_{8} \mathrm{O}_{26}\right]^{4-}\right\}_{n}$ chains running parallel to the crystallographic $a$ axis and bridged along the [010] and [001] directions by the metalorganic linkers following a rectangular grid pattern that leaves individual isolated cavities with a cross section of $c a 4.0 \times$ $7.0 \AA$ (shortest internuclear distances between opposite C atoms) within the space delimited by eight interconnected POM fragments (Fig. 5). Such cavities account for a solventaccessible volume of only $80 \AA^{3}$ ( $6.9 \%$ of the unit-cell volume) and host the water molecules of hydration.

With regard to the thermostructural behaviour, thermogravimetric analyses showed that dehydration (accounting for the 1.5 water molecules per POM determined crystallographically) extends from room temperature to $c a 130{ }^{\circ} \mathrm{C}$ and results in an anhydrous phase with an exceptionally wide range of thermal stability up to a temperature of around $290^{\circ} \mathrm{C}$. Variable-temperature powder X-ray diffraction studies revealed that crystallinity is preserved during dehydration and subsequent range of thermal stability, with the diffraction pattern retained virtually intact throughout the whole process, which evidenced that the unit-cell parameters of the parent compound are fully preserved in the anhydrous derivative. Despite the twinning induced by the thermal evacuation of guest water molecules, the structure of the latter phase could be determined from single-crystal X-ray diffraction measurements performed at $-173{ }^{\circ} \mathrm{C}$ on a crystal of the parent compound that had been heated to $140{ }^{\circ} \mathrm{C}$. These experiments confirmed that the three-dimensional covalent framework of polymeric octamolybdate anions and metalorganic linkers is maintained virtually unaltered upon dehydration, in such a way that the guest-free void cavities in the anhydrous phase were found to be identical to those of the parent compound (Fig. 5, solvent-accessible volume of $75 \AA^{3}$ accounting for $6.6 \%$ of the unit-cell volume). This fact proved the remarkable robustness of the title hybrid framework, and that the lattice water molecules are just fillers that do not play any key structural role in maintaining the crystal packing. 
3. Polyoxometalate-based architectures with dynamic structural response towards dehydration

3.1. Heteropolyacids: a case of crystal packing with spongelike behaviour

The 36-hydrate form of the $\mathrm{H}_{5} \mathrm{PV}_{2} \mathrm{Mo}_{10} \mathrm{O}_{40}$ Keggin-type heteropolyacid dehydrates through a process of three sequential stages, among which the first two involve SCSC transformations into the partially dehydrated intermediates $\mathrm{H}_{5} \mathrm{PV}_{2} \mathrm{Mo}_{10} \mathrm{O}_{40} \cdot 14 \mathrm{H}_{2} \mathrm{O}$ and $\mathrm{H}_{5} \mathrm{PV}_{2} \mathrm{Mo}_{10} \mathrm{O}_{40} \cdot 8 \mathrm{H}_{2} \mathrm{O}$ (BaratsDamatov et al., 2015). The parent compound crystallizes in the monoclinic space group $P 2_{1} / n$ and the asymmetric unit contains one half of a Keggin cluster with the $\mathrm{P}$ atom in a special position and, hence, in the centre of a $\mathrm{PO}_{8}$ cube originating from disorder of the tetrahedral $\mathrm{PO}_{4}$ hetero group over two crystallographically related positions. The $\mathrm{V}$ atoms are randomly disordered over all metal sites and the asymmetric unit is completed by 17 water molecules of hydration in general positions. The unit-cell metrics show a clear tendency towards a tetragonal setting, and indeed a careful inspection of the literature affords a previous structural determination in the space group P4/mnc (Sergienko et al., 1980). The arrangement of clusters follows a checkerboard-like pattern, with P...P distances between adjacent clusters of $c a 12.75 \AA$ and a low packing density of 0.402 [this magnitude is defined by Barats-Damatov et al. (2015) as the fraction of the unit-cell volume occupied by the Keggin-type clusters when they are considered as spheres with an effective van der Waals radius of $5.2 \AA$ ]. Crystals of the title compound of this section were found to undergo immediate partial dehydration into the 14hydrate form upon being removed from the mother liquor and left to dry under ambient conditions. This process was accompanied by crystal cracking, but, nevertheless, the cracked material still retained the features of a single crystal, which allowed for the structure of the 14-hydrate derivative to be determined. This phase shows a completely different unit cell, as it crystallizes in the triclinic space group $P \overline{1}$ with one Keggin cluster and 14 water molecules in the asymmetric unit. No crystallographic disorder was observed in this case and the clusters are arranged in layers stacked along the unit-cell diagonal [101], with the water molecules occupying the interlamellar spaces. The crystal packing was found to be

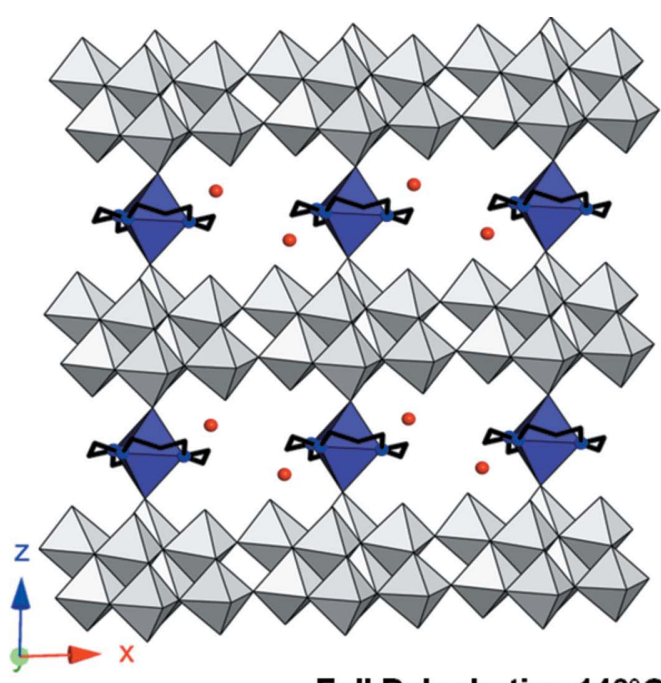

Full Dehydration $140^{\circ} \mathrm{C}$

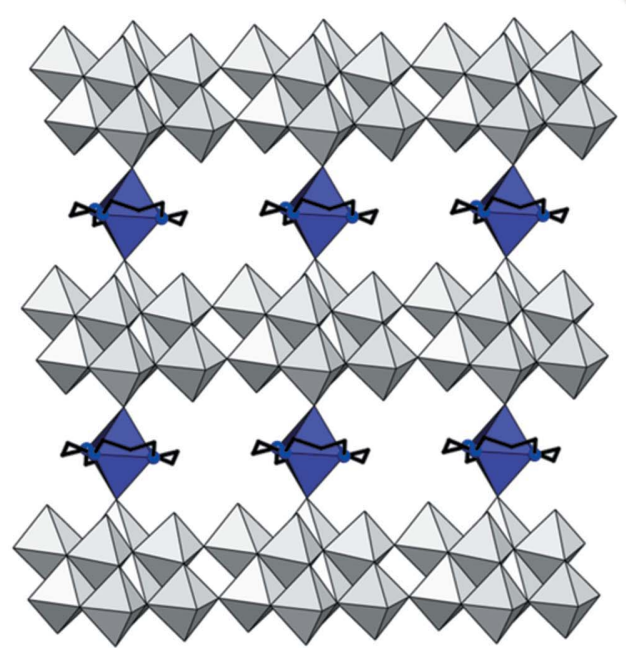

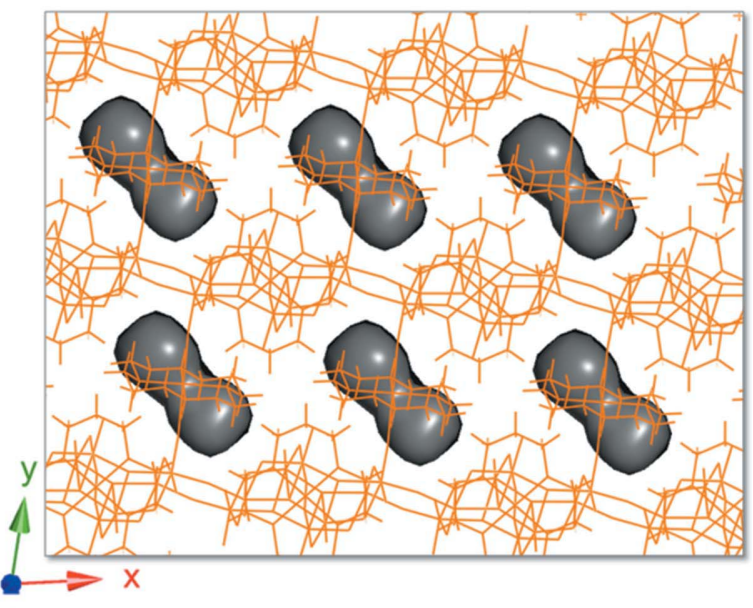

Moisture

Figure 5

Comparison between the crystal packings viewed along the crystallographic $b$ axis ( $\mathrm{H}$ atoms have been omitted for clarity) and solvent-accessible spaces viewed along the crystallographic $c$ axis for $\left[\{\mathrm{Cu}(\text { cyclam })\}_{2}\left(\mathrm{Mo}_{8} \mathrm{O}_{26}\right)\right] \cdot 1.5 \mathrm{H}_{2} \mathrm{O}$ and its anhydrous form $\left[\{\mathrm{Cu}(\mathrm{cyclam})\}_{2}\left(\mathrm{Mo} \mathrm{O}_{26}\right)\right]$. 
substantially more compact than that of the parent compound, in such a way that the P...P distances between neighbouring clusters shortened to $c a 10.55$ (interlamellar) and $9.63 \AA$ (shortest intralamellar), and the packing density consequently increased to 0.564 with a contraction of $c a 29 \%$ in the unit-cell volume (2932 versus $2090 \AA^{3}$ for the 36- and 14-hydrated forms, respectively).

The 8-hydrate form was obtained by thermal dehydration of crystals of the 14 -hydrate phase heated to $40{ }^{\circ} \mathrm{C}$. The asymmetric unit of the triclinic $P \overline{1}$ structure determined from single-crystal X-ray diffraction data collected at $313 \mathrm{~K}$ contains one half of a Keggin cluster with random disorder of the $\mathrm{V}$ atoms over the metal sites and a central $\mathrm{PO}_{8}$ cube originating from the crystallographic disorder of the tetrahedral $\mathrm{PO}_{4}$ hetero group over two centrosymmetricallyrelated positions, as well as four water molecules of hydration (of which one is disordered over two sites). The clusters were packed following a nearly cubic pattern, in good agreement with the clear tendency towards a cubic setting displayed by the triclinic unit-cell metrics. The P...P distances between adjacent clusters were found to be almost identical in all directions (9.82 $\pm 6 \AA$ ) and the water molecules were confined within cubic pockets delimited by eight neighbouring clusters and aligned along the crystallographic $c$ axis. It is worth remarking that this crystal phase is able to undergo a temperature-dependent SCSC transition into a low-temperature polymorph because a different triclinic $P \overline{1}$ unit cell with metrics close to the trigonal system was obtained when the data acquisition was carried out at $120 \mathrm{~K}$ instead of $313 \mathrm{~K}$. In this case, the asymmetric unit is formed by one Keggin cluster with no disorder of the hetero group and eight water molecules that occupy all general positions. The crystal structure of the low-temperature polymorph has been described as a closed hexagonal packing of clusters with a density of 0.64 that is generated by the POM species shifting towards one another upon cooling to form a chess-like arrangement in which the pockets that host the water molecules become misaligned. However, the nearly cubic packing of clusters with aligned pockets observed for the high-temperature phase can still be identified in the low-temperature polymorph upon close inspection of the architecture along the unit-cell diagonals. Owing to the fact that the clusters do not lie on any symmetry element, the two positions over which the hetero group was disordered in the former phase become distinguishable in the latter polymorph, and hence so do the two alternating orientations that the clusters adopt in the packing. Thus, the thermally-triggered polymorphism of the 8-hydrate form appears to originate from an order-disorder transition rather than from any shifting of clusters within the crystal packing. The fact that both the packing density and distances between adjacent clusters are not substantially modified upon cooling (0.627 and $9.88 \pm 9 \AA$ for the low-temperature polymorph) supports the latter interpretation.

Full dehydration of the 20 -hydrate takes place at $c a 100{ }^{\circ} \mathrm{C}$ and results in an amorphous powder, as shown by variabletemperature powder X-ray diffraction studies, but this process was demonstrated to be fully reversible towards the parent 36- hydrate form, with rehydration proceeding with full recovery of the crystallinity. A solid sample of the amorphous anhydrous phase was stored in a wet atmosphere and crystals of the parent 36-hydrate form suitable for single-crystal X-ray diffraction experiments were formed after only $2 \mathrm{~h}$ of exposure. The structure of the parent compound was obtained from the intensity data collected on such a rehydrated sample and the corresponding CIF can be found in the supporting information of Barats-Damatov et al. (2015).

3.2. Ionic hybrid compounds: a case of reversible grafting of metal-organic complexes at the surface of polyoxometalate clusters

Beyond the structural robustness towards dehydration commented on for the microporous crystalline materials in \$2.1, ionic POM-based compounds can also show dynamic behaviour and undergo SCSC transitions triggered by the evacuation of solvent molecules that involve rupture and the formation of coordinative bonds. The SCSC transformations of $\left[\mathrm{Cu}(\right.$ bpmen $\left.)\left(\mathrm{H}_{2} \mathrm{O}\right)\right]\left[\mathrm{SiW}_{12} \mathrm{O}_{40}\{\mathrm{Cu}\right.$ (bpmen) $\left.\}\right]$ (Iturrospe et al., 2013) and $\left[\mathrm{Cu}(\right.$ bpmen $\left.)\left(\mathrm{H}_{2} \mathrm{O}\right)\right]\left[\mathrm{GeW}_{12} \mathrm{O}_{40}\{\mathrm{Cu}(\right.$ bpmen $\left.)\}\right] \cdot-$ $3.5 \mathrm{H}_{2} \mathrm{O}$ (Iturrospe et al., 2014) into their corresponding anhydrous forms $\left[X \mathrm{~W}_{12} \mathrm{O}_{40}\{\mathrm{Cu}(\mathrm{bpmen})\}_{2}\right]$ [bpmen is $N, N^{\prime}$ dimethyl- $N, N^{\prime}$-bis(pyridin-2-ylmethyl)-1,2-diaminoethane] are illustrative examples of this phenomenon.

The Si-containing compound crystallizes in the orthorhombic space group $\mathrm{Pbca}$ with one discrete $\left[\mathrm{SiW}_{12} \mathrm{O}_{40^{-}}\right.$ $\{\mathrm{Cu}$ (bpmen $)\}]^{2-}$ monodecorated Keggin-type anion and one $\left[\mathrm{Cu}(\text { bpmen })\left(\mathrm{H}_{2} \mathrm{O}\right)\right]^{2+}$ charge-compensating complex cation in the asymmetric unit. The $\mathrm{Cu}^{\mathrm{II}}$ centres in both the complex cation and the decorating moiety of the hybrid anion display elongated square-pyramidal coordination geometries, with the $\mathrm{N}_{4}$-donor bpmen ligand in a relative cis conformation forming the basal plane and the apical position occupied by one aqua ligand or one terminal $\mathrm{O}_{\mathrm{POM}}$ atom, respectively. In contrast, the Ge-containing compound crystallizes in the monoclinic space group $P 2_{1} / c$, but its asymmetric unit also contains one $\left[\mathrm{GeW}_{12} \mathrm{O}_{40}\{\mathrm{Cu}(\text { bpmen })\}\right]^{2-}$ and one $\left[\mathrm{Cu}(\text { bpmen })\left(\mathrm{H}_{2} \mathrm{O}\right)\right]^{2+}$ analogous species, as well as 3.5 water molecules of hydration. The crystal packing displays a clear layered nature in both compounds. For the Si-containing compound, the hybrid POM species are held together in rows along the crystallographic $b$ axis through aromatic interactions established with the pyridyl groups of the bpmen ligands, which bend so as to place the aromatic rings parallel to the cluster surfaces at contact distances (Fig. 6). The rows are arranged in corrugated layers that stack along the [001] direction and show intralamellar pockets in which the complex cations are embedded, with the aqua ligand connecting adjacent hybrid POM species in a row via hydrogen bonding. Thus, the layers show a compact packing of hybrid POM species and charge-compensating metal-organic subunits. Analogous structural motifs are displayed by the Ge-containing compound, i.e. rows of hybrid POMs connected through aromatic-cluster interactions that extend along the crystallographic $b$ axis and are arranged in corrugated layers stacked along the [100] direction (Fig. 6). 
However, the need to accommodate the guest water molecules promotes swelling of the compact layers, which results in the hybrid anions separating significantly from each other, the rows adopting an undulating pattern and the complex cations shifting towards the surface of the nearest cluster to stack through aromatic interactions. Thus, the intralamellar pockets in the Si-containing compound become open cavities hosting all water molecules of both hydration and coordination in the Ge-containing derivative.

With regard to the thermostructural behaviour of the title compounds of this section, dehydration is completed at $c a 160$ and $100^{\circ} \mathrm{C}$ for the $\mathrm{Si}$ - and $\mathrm{Ge}$-containing compounds, respectively, and results in anhydrous phases with highly significant range of thermal stability up to temperatures of around $280-290{ }^{\circ} \mathrm{C}$, according to thermogravimetric analyses. Crystallinity is retained throughout the dehydration process and subsequent range of thermal stability, as indicated by variable-temperature powder X-ray diffraction studies, and the diffraction patterns of both anhydrous phases are nearly identical to those of their corresponding parent compounds, which evidenced preservation of the unit-cell parameters without substantial variations upon occurrence of the SCSC transformation. Thanks to dehydration proceeding without loss of crystal integrity, the structures of both anhydrous phases could be determined from single-crystal X-ray diffraction measurements performed at $423 \mathrm{~K}$ on crystals of the parent compounds. As expected from the diffraction patterns, the most relevant modifications were a subtle shortening of length $a$ from 19.547 (2) to 19.325 (2) $\AA$ for the transition of the Si-containing compound, and a slightly more pronounced shortening of the $c$ parameter from 25.843 (5) to 25.3953 (3) $\AA$ for the dehydration of the Ge-containing derivative. The unit-cell volumes were consequently contracted by only ca 80 and $170 \AA^{3}$ (variations of 0.6 and $2.6 \%$, respectively).

These observations could have been indicative of compounds that show robustness towards dehydration and preserve the crystal architecture essentially intact upon evacuation of solvent molecules, as discussed in $\$ 2$, but the structure analyses from single-crystal X-ray diffraction data revealed a dynamic behaviour with formation of coordinative bonds instead. In both cases, the charge-compensating subunits lose their apical aqua ligand, shift towards the nearest cluster and graft at the terminal $\mathrm{O}_{\mathrm{POM}}$ atom that blocks the sixth position of the coordination sphere in the parent hydrated forms to maintain the square-pyramidal geometry (Fig. 6). Therefore, bis(decorated) $\left[X \mathrm{~W}_{12} \mathrm{O}_{40}\{\mathrm{Cu}(\text { bpmen })\}_{2}\right]$ Keggin-based neutral species are formed in both anhydrous
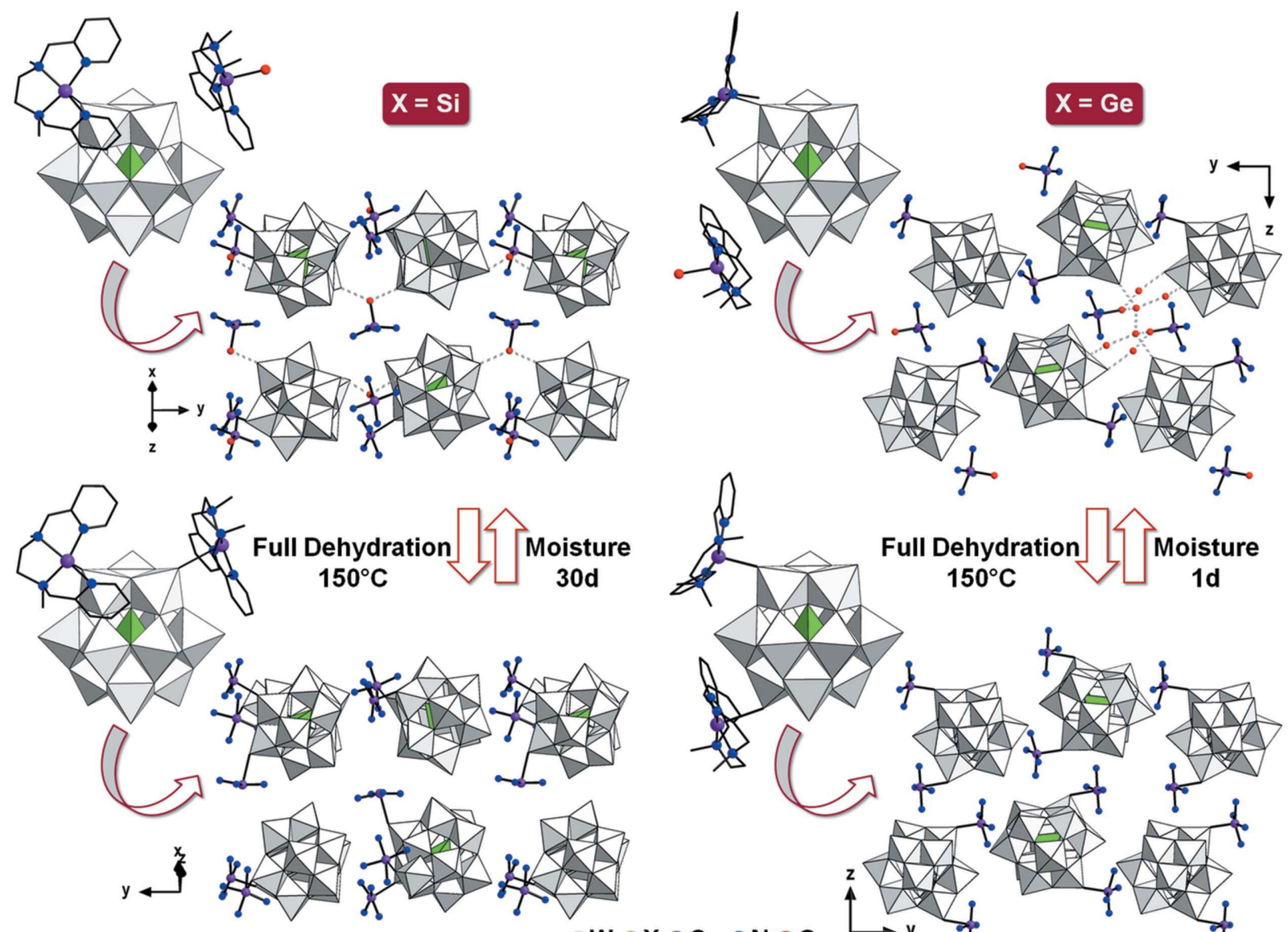

w $\odot$ OCu ON OOW

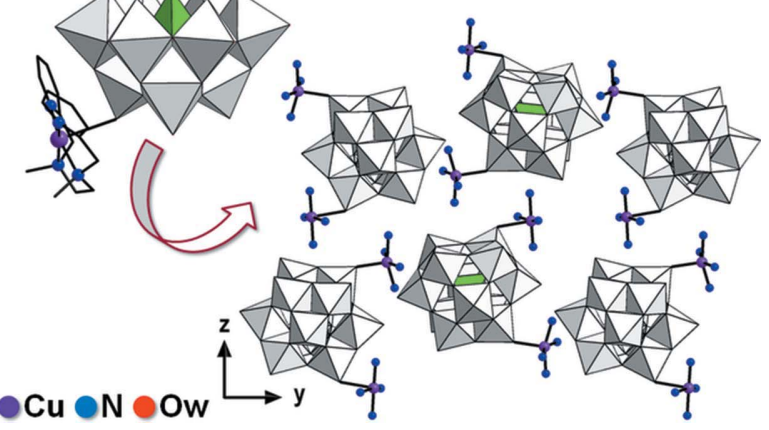

Figure 6

Constituent subunits and hybrid polyoxometalate/metal-organic layers of $\left[\mathrm{Cu}(\mathrm{bpmen})\left(\mathrm{H}_{2} \mathrm{O}\right)\right]\left[X \mathrm{~W}_{12} \mathrm{O}_{40}\{\mathrm{Cu}(\mathrm{bpmen})\}\right] \cdot n \mathrm{H}_{2} \mathrm{O}(X=\mathrm{Si}, n=0 ; X=\mathrm{Ge}, n=$ 3.5) compared with those of the anhydrous forms $\left[X \mathrm{~W}_{12} \mathrm{O}_{40}\{\mathrm{Cu}(\mathrm{bpmen})\}_{2}\right] . \mathrm{H}$ atoms and $\mathrm{C}-\mathrm{C}$ backbones of bpmen ligands have been omitted for clarity and $\mathrm{O}_{\mathrm{w}}-\mathrm{H} \cdots \mathrm{O}_{\mathrm{POM}}$ hydrogen bonds are depicted as dashed gray lines. 
phases, which, nevertheless, belong to different geometrical isomers because of the relative arrangement of hybrid POM anions and complex cations differing in the parent compounds due to the presence of guest solvent molecules in the Gecontaining derivative. Following Pope and Scully's notation (Pope \& Scully, 1975), [SiW ${ }_{12} \mathrm{O}_{40}\left\{\mathrm{Cu}(\text { bpmen) }\}_{2}\right]$ would correspond to the $\alpha(1,2)$ isomer with the decorating moieties grafted at the same $\left\{\mathrm{W}_{3} \mathrm{O}_{13}\right\}$ trimer, whereas $\left[\mathrm{GeW}_{12} \mathrm{O}_{40^{-}}\right.$ $\left.\{\mathrm{Cu}(\text { bpmen })\}_{2}\right]$ would belong to the $\alpha(1,5)$ type with the grafting positions being non-adjacent $\mathrm{WO}_{6}$ octahedra of different trimers. As a result of these dynamics, the crystal architectures of both compounds shrink into a more compact packing of the hybrid POM rows within the layers, which is at the origin of the shortening of the $a$ and $c$ parameters for the $\mathrm{Si}$ - and Ge-containing compounds, respectively. For the latter, this compaction is not enough for the intralamellar hydrophilic cavities to collapse and, therefore, disrupted strings of guest-free slit-shaped micropores with cross sections of $\mathrm{ca} 4.8$ $\times 11.9 \AA$ (internuclear C . . C distances) are formed along the [100] direction ( $\mathrm{ca} 2.6 \%$ of the unit-cell volume).

The reversibility of these SCSC transformations was demonstrated through single-crystal X-ray analyses performed on crystals of the anhydrous phases kept under a humid atmosphere for either one month ( $\mathrm{Si}$ ) or just one day (Ge). In both cases, such crystals afforded the unit-cell para- meters of the corresponding parent hydrated forms and a full structure analysis for the rehydrated Si-containing compound can be found in the Cambridge Structural Database (CSD; Groom et al., 2016) under refcode VEYRIC01 (Iturrospe et al., 2013). In the case of the Ge-containing derivative, partial cracking of the crystal during rehydration did not allow for a full structure analysis to be deposited, but only for a preliminary structure determination to be partially obtained. Nevertheless, rehydration could also be confirmed by thermogravimetric analyses on a crystalline sample of the anhydrous form that was kept under ambient conditions for one day, for which the dehydration curve proved to be virtually identical to that of the parent compound.

\subsection{Neutral polyoxometalate/metal-organic molecular species: a case of organic ligands undergoing conformational rearrangement}

Dynamic behaviour associated with the rupture and formation of coordination bonds triggered by the thermal evacuation of water molecules has also been observed for neutral hybrid species based on POM clusters and metalorganic moieties, such as those in the isostructural compounds $\left[X \mathrm{~W}_{12} \mathrm{O}_{40}\left\{\mathrm{Cu}(\text { bpmpn })\left(\mathrm{H}_{2} \mathrm{O}\right)\right\}_{2}\right] \cdot 3.5 \mathrm{H}_{2} \mathrm{O}(X=\mathrm{Si}, \mathrm{Ge}$; bpmpn is $N, N^{\prime}$-dimethyl- $N, N^{\prime}$-bis(pyridin-2-ylmethyl)-1,3-diaminopro-
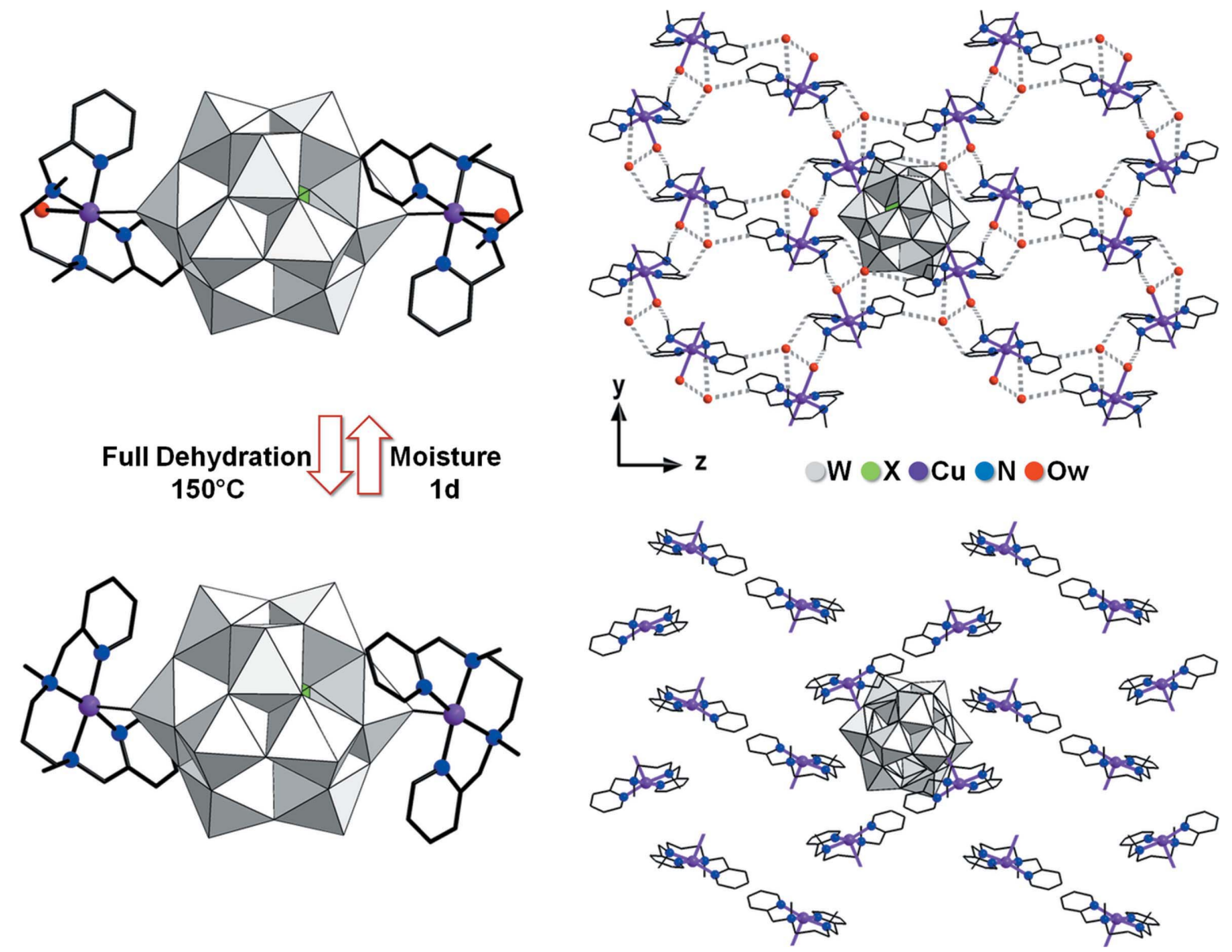

Figure 7

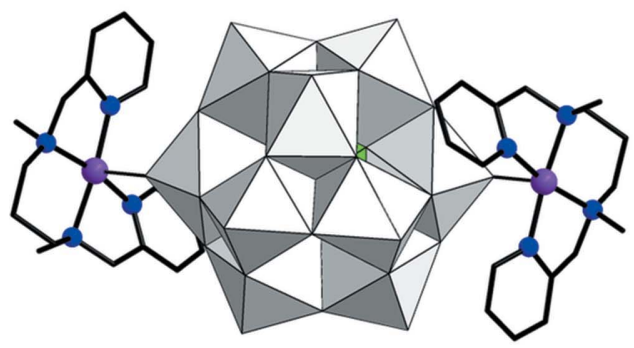

Comparison between the hybrid bis(decorated) neutral species and the metal-organic regions projected on the crystallographic $b c$ plane for $\left[X \mathrm{~W}_{12} \mathrm{O}_{40}\left\{\mathrm{Cu}(\mathrm{bpmpn})\left(\mathrm{H}_{2} \mathrm{O}\right)\right\}_{2}\right] \cdot 3 \mathrm{H}_{2} \mathrm{O}(X=\mathrm{Si}, \mathrm{Ge})$ and their anhydrous forms $\left[X \mathrm{~W}_{12} \mathrm{O}_{40}\{\mathrm{Cu}(\mathrm{bpmpn})\}_{2}\right] . \mathrm{H}$ atoms have been omitted for clarity and $\mathrm{O}_{\mathrm{w}}-$ $\mathrm{H} \cdots \mathrm{O}_{\mathrm{POM}}$ and $\mathrm{C}-\mathrm{H} \cdots \mathrm{O}_{\mathrm{w}}$ hydrogen bonds are depicted as dashed gray lines. 
pane), which were found to fully dehydrate through an SCSC transformation process resulting in the $\left[X \mathrm{~W}_{12} \mathrm{O}_{40}[\mathrm{Cu}-\right.$ (bpmpn) $\}_{2}$ ] anhydrous phases (Iturrospe et al., 2013, 2014). The title compounds of the section crystallize in the monoclinic space group $P 2_{1} / n$ with the bis(decorated) $\left[X \mathrm{~W}_{12} \mathrm{O}_{40^{-}}\right.$ $\left.\left\{\mathrm{Cu}(\text { bpmpn })\left(\mathrm{H}_{2} \mathrm{O}\right)\right\}_{2}\right]$ neutral species located on a centre of inversion and three water molecules of hydration in general positions. The former species is composed of one $\alpha$-Keggin cluster and two $\left\{\mathrm{Cu}(\mathrm{bpmpn})\left(\mathrm{H}_{2} \mathrm{O}\right)\right\}^{2+}$ decorating moieties anchored at opposite terminal $\mathrm{O}_{\mathrm{POM}}$ atoms in which the $\mathrm{Cu}^{\mathrm{II}}$ centres show elongated octahedral coordination geometries with the $\mathrm{N}_{4}$-donor bpmpn ligand in the basal plane and the remaining axial position occupied by one aqua ligand. The bpmpn ligands are in a trans conformation, with the methyl groups of the amine functionalities pointing to opposite sides of the $\mathrm{CuN}_{4}$ plane, and their arrangement with respect to the Keggin cluster allows for intramolecular aromatic interactions between the pyridyl rings and the cluster surface to be established. The packing of such neutral POM species leads to a succession of alternating laminar regions of clusters and metal-organic moieties parallel to the $(10 \overline{1})$ plane. The metalorganic sheets contain strings of complexes connected in a honeycomb-like pattern via $\mathrm{C}-\mathrm{H} \cdots \mathrm{O}_{\mathrm{w}}$ interactions involving methyl groups, aqua ligands and water molecules of hydration (Fig. 7), whereas the inorganic sheets consist of a hexagonal tiling of clusters hydrogen bonded by interstitial water molecules. The packing of these sheets along the crystallographic $a$ axis is such that the centres of the metal-organic hexagons are placed over the clusters. With regard to the thermostructural behaviour of the title compounds, dehydration is completed at $\mathrm{ca} 145$ and $130{ }^{\circ} \mathrm{C}$ for the Si- and Ge-containing compounds, respectively, and results in anhydrous phases with a noteworthy range of thermal stability up to temperatures of ca 255 and $270{ }^{\circ} \mathrm{C}$, according to thermogravimetric analyses. Variable-temperature powder X-ray diffraction studies show that crystallinity is retained throughout the whole dehydration process and subsequent range of thermal stability, and that the diffraction patterns of the anhydrous phases are nearly identical to those of the parent compounds, which evidences preservation of the unit-cell parameters upon the SCSC transition without substantial variations. Thanks to dehydration proceeding without loss of crystal integrity, the structures of both anhydrous phases could be determined from singlecrystal X-ray diffraction measurements performed at $423 \mathrm{~K}$ on crystals of the parent compounds. As expected from the diffraction patterns, the most relevant modification in the unitcell parameters was the shortening of the length $c$ by only $c a$ $0.5 \AA$, which was accompanied by a contraction of the unit-cell volume by ca $4 \%\left(\right.$ ca $\left.130 \AA^{3}\right)$.

As for the two compounds discussed in the previous section, the preservation of the unit-cell parameters upon the crystal phase transition was not found to be indicative of any structural robustness, but concealed a dynamic behaviour instead. The relative arrangement of the Keggin cluster and its two decorating metal-organic moieties is maintained in the neutral species present in the anhydrous phases, but the latter undergo major changes upon dehydration (Fig. 7). Besides the coor- dination geometry of the $\mathrm{Cu}^{\mathrm{II}}$ centres becoming squarepyramidal upon loss of the aqua ligand with consequent shortening of the $\mathrm{Cu}-\mathrm{O}_{\mathrm{POM}}$ bond, the bpmpn ligand transforms from a trans to a cis conformer, with the methyl groups pointing to the same side of the $\mathrm{CuN}_{4}$ plane, and the occurrence of such a conformational rearrangement can only take place via rupture of a $\mathrm{Cu}-\mathrm{N}$ bond involving an amine functionality, rotation of the latter and re-coordination. Although the overall crystal architecture is also preserved upon dehydration, the release of all types of water molecules promotes: (i) a much tighter packing of the clusters in the inorganic sheets, which is at the origin of the shortening of the $c$ parameter and consequent contraction of the unit-cell volume; (ii) the replacement of the network of weak intermolecular interactions within the metal-organic sheets by a new set of $\mathrm{C}-\mathrm{H} \cdot \mathrm{O}_{\mathrm{POM}}$ contacts, which is formed upon approach of the $\left\{\mathrm{Cu}(\text { bpmpn })\left(\mathrm{H}_{2} \mathrm{O}\right)\right\}^{2+}$ moieties to the cluster surfaces due to compression of the metal-organic hexagons. The trans-to-cis conformational change of the bpmpn ligands facilitates the formation of such $\mathrm{C}-\mathrm{H} \cdots \mathrm{O}_{\mathrm{POM}}$ contacts in the anhydrous phases.

The reversibility of the SCSC transitions was confirmed by single-crystal X-ray diffraction analyses performed on crystals of the anhydrous phases kept under a humid atmosphere for either one month $(\mathrm{Si})$ or one day $(\mathrm{Ge})$. In both cases, such crystals afforded the unit-cell parameters of the corresponding hydrated forms, and despite partial crystal cracking that prevented full structure analyses suitable for publication to be achieved, preliminary structure determinations allowed for the parent bis(decorated) species, with the bpmpn ligands in a trans conformation, to be observed. Nevertheless, rehydration could also be confirmed by thermogravimetric analyses on crystalline samples of the anhydrous forms that were left under ambient conditions for one day, for which the dehydration curves proved to be virtually identical to those of the parent compounds.

\subsection{A case of metal-organic complexes dissociating within a rigid polyoxometalate-based architecture}

An additional example of bonding disruption within a crystal architecture that is essentially preserved upon evacuation of solvent molecules can be found in the isostructural compounds $\left[\mathrm{C}\left(\mathrm{NH}_{2}\right)_{3}\right]_{4}\left[\left\{X \mathrm{~W}_{12} \mathrm{O}_{40}\right\}\left\{\mathrm{Cu}_{2}(\text { pic })_{4}\right\}\right] \cdot 2\left[\mathrm{Cu}_{2}(\text { pic })_{4}{ }^{-}\right.$ $\left.\left(\mathrm{H}_{2} \mathrm{O}\right)\right] \cdot 6 \mathrm{H}_{2} \mathrm{O}(X=\mathrm{Si}, \mathrm{Ge}$; pic is 2-picolinate), which undergo SCSC transformation into the phases $\left[\mathrm{C}\left(\mathrm{NH}_{2}\right)_{3}\right]_{4}\left[\left\{X \mathrm{~W}_{12} \mathrm{O}_{40}\right\}-\right.$ $\left.\left\{\mathrm{Cu}_{2}(\text { pic })_{4}\right\}\right] \cdot 4\left[\mathrm{Cu}(\text { pic })_{2}\right]$ upon full dehydration (Pache et al., 2015). The title compounds of this section crystallize in the triclinic space group $P \overline{1}$ with the following fragments in the asymmetric unit: one half of a $\left[X \mathrm{~W}_{12} \mathrm{O}_{40}\right]^{4-}$ Keggin cluster, one half of a $\left[\mathrm{Cu}_{2}(\text { pic })_{4}\right]$ dinuclear complex supported on the cluster, two halves of an isolated $\left[\mathrm{Cu}_{2}(\text { pic })_{4}\left(\mathrm{H}_{2} \mathrm{O}\right)\right]$ dimer, two guanidinium cations and three water molecules of hydration. All of the $\mathrm{Cu}^{\mathrm{II}}$ atoms show axial-type coordination geometries with two trans-related pic ligands forming the basal/equatorial plane. The $\left[\mathrm{Cu}_{2}(\mathrm{pic})_{4}\right]$ complex is composed of two $\left\{\mathrm{Cu}(\mathrm{pic})_{2}\right\}$ moieties, with the copper centres involved in elongated octa- 
hedral geometries and linked into a $\mathrm{Cu}_{2} \mathrm{O}_{2}$ rhomboid core by two pic ligands acting in an equatorial-axial $\mu_{2}-\kappa^{2} N, O: \kappa^{1} O$ bridging mode. Terminal $\mathrm{O}_{\mathrm{POM}}$ atoms occupy the remaining axial positions. In contrast, the isolated $\left[\mathrm{Cu}_{2}(\mathrm{pic})_{4}\left(\mathrm{H}_{2} \mathrm{O}\right)\right]$ dimer is formed by one $\left\{\mathrm{Cu}(\text { pic })_{2}\right\}$ and one $\left\{\mathrm{Cu}(\text { pic })_{2}\left(\mathrm{H}_{2} \mathrm{O}\right)\right\}$ moiety, with the copper centres involved in elongated squarepyramidal geometries and linked by a single pic ligand acting in a $\mu_{2}-\kappa^{2} N, O: \kappa^{1} O^{\prime}$ mode, the apical positions being occupied by the bridging $\mathrm{O}_{\text {pic }}$ atom and one aqua ligand. The crystal packing displays a pronounced layered character, with hybrid and metal-organic sheets stacked alternately along the crystallographic $c$ axis (Fig. 8). The hybrid sheets are formed by one-dimensional $\left[\left\{X \mathrm{~W}_{12} \mathrm{O}_{40}\right\}\left\{\mathrm{Cu}_{2}(\mathrm{pic})_{4}\right\}\right]^{4-}$ assemblies that are arranged in a parallel fashion along the [110] direction. The metal-organic sheets contain all of the isolated $\left[\mathrm{Cu}_{2}(\mathrm{pic})_{4^{-}}\right.$ $\left(\mathrm{H}_{2} \mathrm{O}\right)$ ] dimers, water molecules and guanidinium cations, which form a massive network of $\mathrm{N}-\mathrm{H} \cdots \mathrm{O}_{\text {pic }}$ hydrogen bonds with the carboxylate functionalities of the three crystallographically independent $\left\{\mathrm{Cu}(\text { pic })_{2}\right\}$ fragments.
With regard to the thermostructural behaviour, dehydration extends from room temperature to $\mathrm{ca} 130{ }^{\circ} \mathrm{C}$ and results in anhydrous phases with remarkable thermal stability up to $c a$ $300{ }^{\circ} \mathrm{C}$ according to thermogravimetric analyses. Crystallinity is retained throughout the whole dehydration process and subsequent range of thermal stability, as confirmed by variable-temperature powder X-ray diffraction analyses, and the diffraction pattern of the parent hydrated compounds is preserved with negligible variations for the resulting anhydrous phases, which indicates that the evacuation of water molecules does not affect the unit-cell metrics significantly. The structures of the isostructural anhydrous phases could both be determined from single-crystal X-ray diffraction experiments performed on crystals of the parent compounds that were slowly heated to $140{ }^{\circ} \mathrm{C}$ to generate the anhydrous form and subsequently cooled to $-173{ }^{\circ} \mathrm{C}$ to carry out the full intensity data collection. The most relevant change found in the unit-cell parameters upon dehydration was a shortening of length $c$ [from 17.0285 (5) to 15.99845 (7) $\AA$ for the $\mathrm{Si}$ -
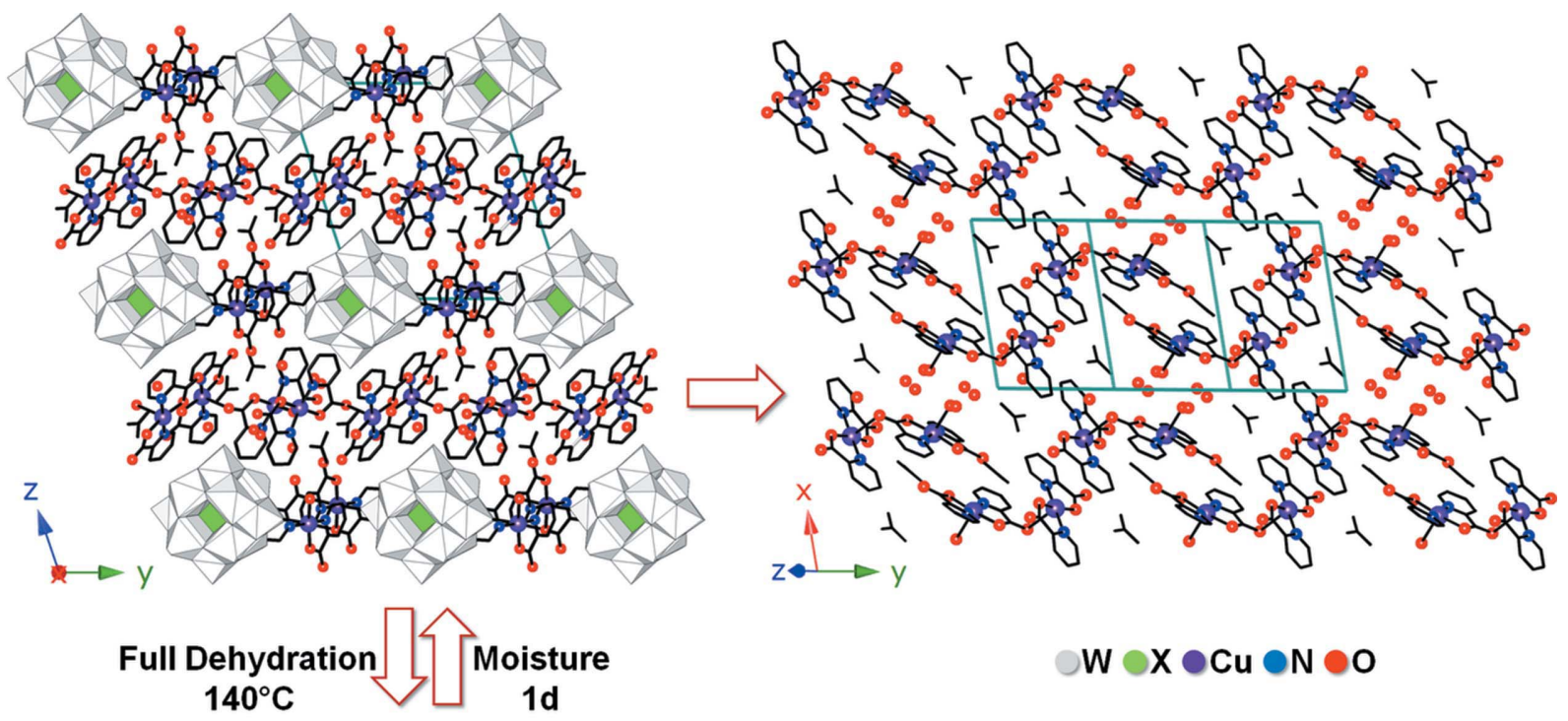

W $\odot$ X $\bullet \mathrm{Cu} \odot \mathrm{O}$
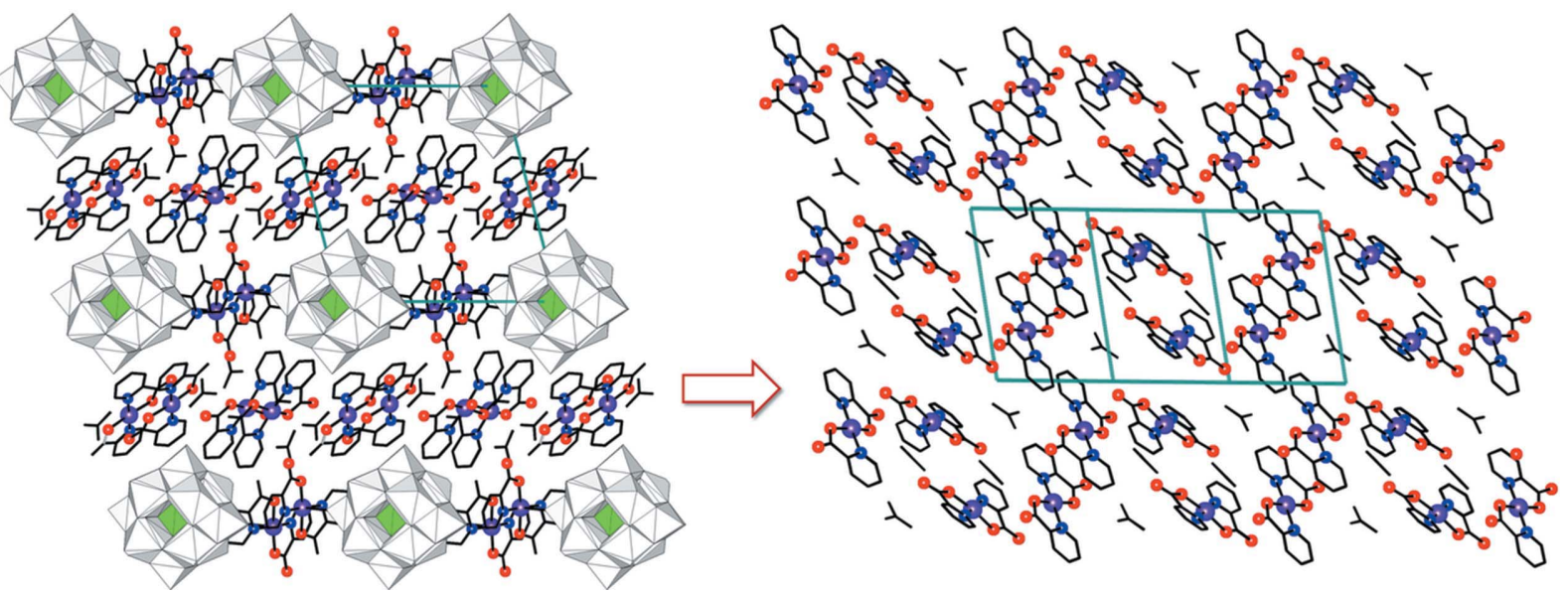

Figure 8

Crystal packing viewed along the crystallographic $a$ axis and metal-organic sheets projected on the $(012)$ plane for $\left[\mathrm{C}\left(\mathrm{NH}_{2}\right)_{3}\right]_{4}\left[\left\{X \mathrm{XW}_{12} \mathrm{O}_{40}\right\}\left\{\mathrm{Cu} \mathrm{u}_{2}\right.\right.$ (pic) $\left.\left.)_{4}\right\}\right] \cdot 2\left[\mathrm{Cu}_{2}(\text { pic })_{4}\left(\mathrm{H}_{2} \mathrm{O}\right)\right] \cdot 6 \mathrm{H}_{2} \mathrm{O}(X=\mathrm{Si}, \mathrm{Ge})$ compared with those in the anhydrous forms $\left[\mathrm{C}\left(\mathrm{NH}_{2}\right)_{3}\right]_{4}\left[\left\{X \mathrm{~W}_{12} \mathrm{O}_{40}\right\}\left\{\mathrm{Cu}_{2}(\text { pic })_{4}\right\}\right] \cdot 4\left[\mathrm{Cu}(\text { pic })_{2}\right] \cdot \mathrm{H}$ atoms have been omitted for clarity. 
containing compound], which was accompanied by a contraction of the unit-cell volume ( $c a 140 \AA^{3}$, accounting for a variation of $4.7 \%$ ).

Owing to the metal-organic sheets hosting all the water molecules of both coordination and hydration, the hybrid sheets were found to be unaffected by the thermal dehydration process and to remain fully intact in the anhydrous phases. In contrast, loss of the aqua ligand in the isolated $\left[\mathrm{Cu}_{2}(\text { pic })_{4}\left(\mathrm{H}_{2} \mathrm{O}\right)\right]$ dimer and the release of the water molecules of hydration in the vicinity were found to promote dissociation of the dinuclear entity, which splits into two independent $\left[\mathrm{Cu}(\text { pic })_{2}\right]$ square-planar complexes due to the disruption of the bridging $\mathrm{Cu}-\mathrm{O}_{\text {pic }}$ apical bond, as evidenced by its significant lengthening from a value typical of an elongated square-pyramidal geometry $[2.488(8) \AA]$ to a value far beyond the limits of coordination $[3.310(8) \AA]$. The resulting $\left[\mathrm{Cu}(\text { pic })_{2}\right]$ monomers spread on the crystallographic $a b$ plane to fill the space left vacant by the water molecules and this motion makes the corrugated metal-organic sheets in the parent compounds become nearly planar in the anhydrous

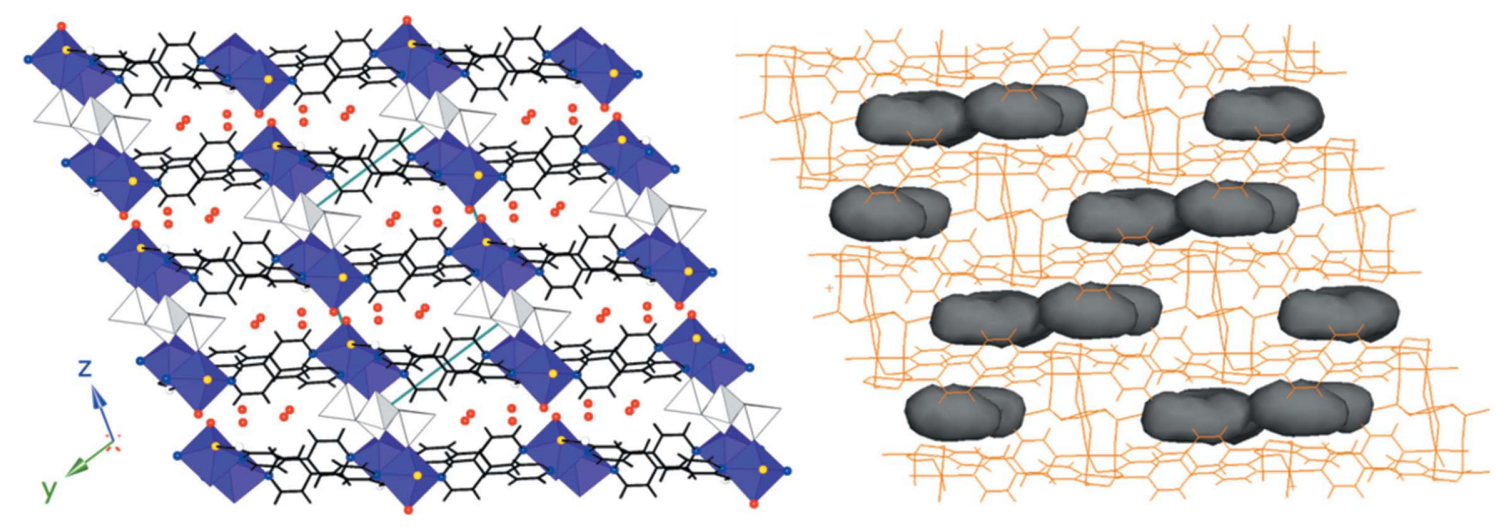

$\underset{150^{\circ} \mathrm{C}}{\text { Partial Dehydration }} \begin{gathered}\text { Moisture } \\ 7 \mathrm{~d}\end{gathered}$

O $\odot$ Co $\odot$ N O OW
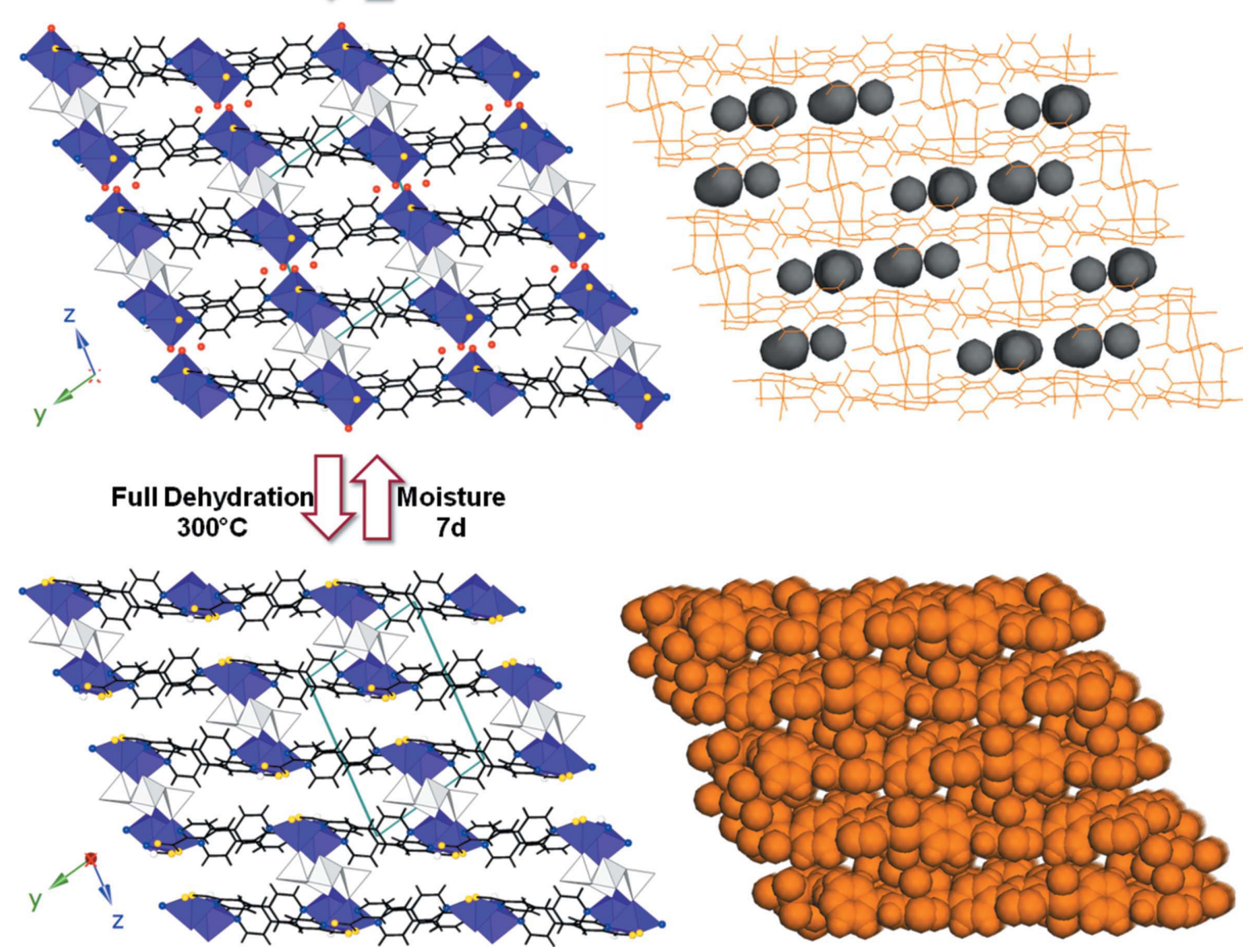

Figure 9

Comparison between the crystal packings and solvent-accessible spaces viewed along the crystallographic $a$ axis for $\left[\mathrm{Co}_{4}\left(\mathrm{ppca}_{4}\left(\mathrm{H}_{2} \mathrm{O}\right)_{2}\left(\mathrm{~V}_{4} \mathrm{O}_{12}\right)\right] \cdot 7.2 \mathrm{H}_{2} \mathrm{O}\right.$, its partially dehydrated derivative $\left[\mathrm{Co}_{4}(\mathrm{ppca})_{4}\left(\mathrm{H}_{2} \mathrm{O}\right)_{2}\left(\mathrm{~V}_{4} \mathrm{O}_{12}\right)\right] \cdot 1.1 \mathrm{H}_{2} \mathrm{O}$ and the anhydrous form $\left[\mathrm{Co}_{4}(\mathrm{ppca})_{4}\left(\mathrm{~V}_{4} \mathrm{O}_{12}\right)\right]$. 
phases, which allows for a more compact stacking of the sheets and shortens parameter $c$ as a result (Fig. 8). In spite of this complex dissociation, the structure-directing network of $\mathrm{N}-$ $\mathrm{H}$... O hydrogen bonds remains almost intact upon dehydration because of a slight reorientation of the guanidinium cations to preserve almost all contacts. This fact reveals the key role of these cations in preserving the crystallinity of the architecture and allowing for the SCSC transformation to take place.

The reversibility of the SCSC transformations was demonstrated by single-crystal X-ray diffraction analyses performed on the same crystals used for determining the structure of the anhydrous phases upon being stored under ambient conditions for a few days. Such crystals afforded the unit-cell parameters of the parent hydrated forms when used for a new data collection at $100 \mathrm{~K}$, and both the inorganic and metalorganic subunits could be located back in their original positions when such data were analyzed. Rehydration was also confirmed by thermogravimetric analyses on crystalline samples of the anhydrous forms that were kept under ambient conditions for one day, for which the dehydration curves proved to be virtually identical to those of the parent compounds.

\subsection{Crystal dynamics in hybrid polyoxometalate/metal- organic extended frameworks undergoing sequential trans- formations}

Thermal dehydration does not only trigger SCSC transition processes of a dynamic nature in ionic or molecular POMbased species, such as the examples commented in the sections above, but they are also known for extended covalent frameworks in which the evacuation of water molecules promotes significant rearrangement in the crystal architecture due to modification of the covalent bonding scheme. [ $\mathrm{Co}_{4}$ (ppca) $\left.)_{4}\left(\mathrm{H}_{2} \mathrm{O}\right)_{2}\left(\mathrm{~V}_{4} \mathrm{O}_{12}\right)\right] \cdot 7.2 \mathrm{H}_{2} \mathrm{O}$ [ppca is 4-(pyridin-4-yl)pyridine-2-carboxylate] constitutes an illustrative example of such a type of dynamic POM-based framework as it undergoes two sequential SCSC transformations triggered by thermal dehydration, leading to the partially dehydrated derivative $\left[\mathrm{Co}_{4}(\text { ppca })_{4}\left(\mathrm{H}_{2} \mathrm{O}\right)_{2}\left(\mathrm{~V}_{4} \mathrm{O}_{12}\right)\right] \cdot 1.1 \mathrm{H}_{2} \mathrm{O}$ first, and then to the anhydrous phase $\left[\mathrm{Co}_{4}(\mathrm{ppca})_{4}\left(\mathrm{~V}_{4} \mathrm{O}_{12}\right)\right]$, with changes in the $\mathrm{Co}^{\mathrm{II}}$ coordination geometry (Chen et al., 2005).

The parent compound crystallizes in the triclinic space group $P \overline{1}$ with one half of a $\left[\mathrm{V}_{4} \mathrm{O}_{12}\right]^{4-}$ anion, two crystallographically independent $\mathrm{Co}^{\mathrm{II}}$ centres, two ppca ligands, one water molecule of coordination and four general sites suitable for water molecules of hydration (of which one refined with a population factor of 0.6 ) in the asymmetric unit. Both $\mathrm{Co}^{\mathrm{II}}$ centres display octahedral $\mathrm{CoO}_{4} \mathrm{~N}_{2}$ coordination geometries with the following donor atoms in common: the $O, N$-chelating picolinate group of one ppca ligand in equatorial positions, the $\mathrm{N}$ atom from the pyridyl group of a second ppca ligand (transrelated to the $\mathrm{N}_{\text {pic }}$ atom), the $\mathrm{O}$ atom from a $\left[\mathrm{V}_{4} \mathrm{O}_{12}\right]^{4-}$ anion in an axial position and the $\mathrm{O}$ atom from the carboxylate group of a third ppca ligand. The sixth site in the coordination sphere is occupied either by a second $\mathrm{O}_{\mathrm{POM}}$ atom (Co1) or by a terminal aqua ligand $(\mathrm{Co} 2)$. The $\mathrm{O}_{\mathrm{POM}}$ atoms are in a rela- tive cis arrangement for Co1 and the octahedral geometry shows a slight distortion (CShM, i.e. continuous shape measure; Alvarez et al., 2002) value of 0.391 , with the ideal octahedron as the reference shape), whereas the $\mathrm{O}_{\mathrm{COO}}$ atom occupies an axial position in the coordination sphere of $\mathrm{Co} 2$ and the distortion from an ideal octahedron becomes much larger (CShM value of 1.883). Thus, the ppca ligands chelate one $\mathrm{Co}^{\mathrm{II}}$ ion through the picolinate group and coordinate two further $\mathrm{Co}^{\mathrm{II}}$ centres in a monodentate fashion via the pyridyl group and the second $\mathrm{O}_{\mathrm{COO}}$ atom in a syn-anti carboxy mode, in such a way that they act as $\mu_{3}-\left(\kappa^{4} N, O: N^{\prime}: O^{\prime}\right)$ linkers, leading to the formation of two-dimensional $\mathrm{Co} /$ ppca covalent lattices parallel to the $(0,7, \overline{13})$ plane. These metal-organic layers are crosslinked by cyclic $\left[\mathrm{V}_{4} \mathrm{O}_{12}\right]^{4-}$ anions with chair conformation in such a way that one-dimensional $\mathrm{Co} / \mathrm{V}_{4}$ covalent assemblies are formed along the [100] direction. The crosslinking of metal-organic $\mathrm{Co} /$ ppca layers and inorganic $\mathrm{Co} / \mathrm{V}_{4}$ chains results in a three-dimensional covalent hybrid framework with rectangular channels of a ca $5.6 \times 17.1 \AA$ cross section ( $\mathrm{Co} \cdots \mathrm{Co}$ and $\mathrm{O}_{\mathrm{POM}} \cdots \mathrm{O}_{\mathrm{POM}}$ internuclear distances) parallel to the crystallographic $a$ axis (Fig. 9). These channels are arranged following a brick-wall motif and represent $15 \%$ of the unit-cell volume. The aqua ligands of $\mathrm{Co} 2$ point towards the centre of the channels and bisect the solvent-accessible space in which all of the water molecules of hydration are hosted.

The parent compound can undergo loss of guest water molecules with retention of the single-crystal character when heated to $150{ }^{\circ} \mathrm{C}$ for one day. Single-crystal X-ray diffraction experiments revealed that such a partially dehydrated derivative crystallizes with a virtually identical unit cell but for a slight decrease in the $b$ length [from 11.3068 (6) to 10.8844 (9) §] accompanied by slight decrease of the unit-cell volume (from 1411 to $1336 \AA^{3}$ ). The octahedral geometries around the $\mathrm{Co}^{\mathrm{II}}$ centres remain almost unaltered upon dehydration (CShM values of 0.321 for $\mathrm{Co} 1$ and 2.075 for $\mathrm{Co} 2$ ), as does the relative arrangement of the $\mathrm{Co}^{\mathrm{II}}$ nodes, ppca connectors and vanadate crosslinkers in the three-dimensional covalent framework (Fig. 9). The solvent-accessible space in the channels shrinks to $12 \%$ of the unit-cell volume due to the evacuation of all of the water molecules of hydration, with the exception of those hydrogen bonded to the aqua ligands of the Co2 centres, which appear to act as pillars essential for maintaining the integrity of the rectangular channels.

The anhydrous phase is obtained through a second SCSC transition when the crystals are heated to higher temperatures $\left(300{ }^{\circ} \mathrm{C}\right.$ for $2 \mathrm{~h}$ ). In spite of crystallizing also in the triclinic space group $P \overline{1}$ with analogous metal-organic and inorganic fragments in the asymmetric unit, the origin and orientation of the unit cell of the resulting phase is modified when compared to those of the parent compound and the partially dehydrated derivative, and the $b$ length is further shortened to 10.3376 (9) A. While Co1 remains octahedrally coordinated with a similar slight distortion (CShM value of 0.348 ), the $\mathrm{Co} 2$ centre becomes five-coordinated and shows a highly distorted geometry that is best described as trigonal bipyramidal because, even if the CShM value is as high as 2.490 , it is still 
much lower than those obtained for any other ideal fivecoordinated shape. The solvent-accessible channels nearly collapse as the void space decreases to less than $6 \%$ of the unit-cell volume (Fig. 9) and, considering that the variation of this parameter is only $40 \AA^{3}$ and that the $\mathrm{Co} / \mathrm{V}_{4}$ chains along the [100] direction are not modified, such a collapse can only be attributed to a rearrangement of the ppca ligands within the metal-organic layers, which are now parallel to the (012) plane, as well as to a shear motion of the latter upon loss of the pillars represented by the aqua ligands.

The dehydration-triggered crystal dynamics of $\left[\mathrm{Co}_{4}(\mathrm{ppca})_{4}{ }^{-}\right.$ $\left.\left(\mathrm{H}_{2} \mathrm{O}\right)_{2}\left(\mathrm{~V}_{4} \mathrm{O}_{12}\right)\right] \cdot 7.2 \mathrm{H}_{2} \mathrm{O}$ are accompanied by chromic properties, as its SCSC transformations into the anhydrous phase through the partially dehydrated intermediate involve colour changes from dark red to brown that originate from $\mathrm{Co} 2$ centres becoming five-coordinated upon loss of the aqua ligands. The thermal evacuation of water molecules and the consequent solvatochromism and crystal-phase transitions have been demonstrated to be fully reversible by immersion of crystals of the partially dehydrated or anhydrous forms in water, as well as by exposure to ambient moisture for less than one week. Single-crystal X-ray diffraction analyses on such crystals showed that the original structure was reconstituted, and the corresponding CIFs can be found in the CSD with the refcodes SAVWAO01 and SAVWAO02 (Chen et al., 2005), respectively.

The first three-dimensional covalent architecture constructed from heptatungstate clusters and metal-organic linkers, namely $\left[\{\mathrm{Cu}(\text { cyclam })\}_{3}\left(\mathrm{~W}_{7} \mathrm{O}_{24}\right)\right] \cdot 15.5 \mathrm{H}_{2} \mathrm{O}$, constitutes another example of a microporous POM-based hybrid framework with crystal dynamics triggered by thermal dehydration. This compound dehydrates also via two sequential SCSC transitions leading to the final $[\mathrm{Cu}(\text { cyclam })]_{0.5}[\{\mathrm{Cu}(\mathrm{cy}-$ clam $)\}_{2.5}\left(\mathrm{~W}_{7} \mathrm{O}_{24}\right)$ ] layered anhydrous phase through the partially dehydrated intermediate $\left[\{\mathrm{Cu}(\text { cyclam })\}_{3}\left(\mathrm{~W}_{7} \mathrm{O}_{24}\right)\right]$-$12 \mathrm{H}_{2} \mathrm{O}$, but in contrast to what was described for the vanadatebased compound above, the evacuation of guest water molecules and consequent crystal-phase transitions do not imply full loss of the porosity in this case (Martín-Caballero et al., 2017). The parent compound crystallizes in the triclinic space group $P \overline{1}$, with one $\left[\mathrm{W}_{7} \mathrm{O}_{24}\right]^{6-}$ anion, one $\{\mathrm{Cu}(\text { cyclam })\}^{2+}$ linking moiety in a general position, four halves of another four centrosymmetric $\{\mathrm{Cu}(\text { cyclam })\}^{2+}$ linking moieties and 15.5 lattice water molecules disordered over 20 crystallographic sites in the asymmetric unit. All the $\mathrm{Cu}^{\mathrm{II}}$ centres show elongated octahedral coordination geometries, with the $\mathrm{N}_{4}$-donor cyclam ligand in a trans-III configuration forming the equatorial plane and terminal $\mathrm{O}_{\mathrm{POM}}$ atoms occupying the axial positions. The crystal packing contains hybrid layers parallel to the crystallographic ac plane in which the centrosymmetric $\{\mathrm{Cu}(\text { cyclam })\}^{2+}$ linking moieties connect the POM units in the [101] and [10̄1] directions following a rhombic-like grid pattern in which contiguous clusters are arranged alternately in such a way that the cleft of the V-shaped $\left[\mathrm{W}_{7} \mathrm{O}_{24}\right]^{6-}$ anion points either above or below the mean plane of the layer. The hybrid layers stack along the crystallographic $b$ axis with superimposed rhombic grid voids, which generates channels with a cross section of $c a 10.1 \times 9.4 \AA$ (shortest internuclear distances between opposite $\mathrm{N}$ atoms) that are interconnected along the [100] direction in a two-dimensional system of crosslinked solvent-accessible spaces $\left(1070 \AA^{3}, c a\right.$ $30 \%$ of the unit-cell volume) hosting all the water molecules of hydration (Fig. 10). This architecture resembles closely that commented on in $\$ 2.2$ for the supramolecular open-framework $[\mathrm{Cu}($ cyclam $)]\left[\{\mathrm{Cu}(\text { cyclam })\}_{2}\left(\mathrm{~V}_{10} \mathrm{O}_{28}\right)\right] \cdot 10 \mathrm{H}_{2} \mathrm{O}$, in which the stacking of square-like hybrid grids is cemented by interlamellar charge-compensating complexes via extensive hydrogen bonding, but for the fact that the interlamellar $\{\mathrm{Cu}(\text { cyclam })\}^{2+}$ moieties in this case act also as covalent linkers that connect the hybrid rhombic-like grids into a threedimensional covalent open framework through axial coordination. It is worth remarking in this context that, while covalent frameworks are usually considered as displaying superior rigidity towards the evacuation of guest solvent molecules than do supramolecular systems, it is the existence of a collection of co-operative weak $X-\mathrm{H} \cdots \mathrm{O}_{\mathrm{POM}}(X=\mathrm{N}, \mathrm{C})$ intermolecular interactions that provides this type of architecture with robustness towards dehydration rather than the existence of coordinative bonds, which results in flexibility and consequent crystal dynamics instead.

With regard to the thermostructural behaviour, dehydration is completed at $c a 80^{\circ} \mathrm{C}$ and results in an anhydrous phase with a range of thermal stability up to $c a 300{ }^{\circ} \mathrm{C}$, as shown by thermogravimetric analyses. According to variable-temperature powder X-ray diffraction studies, the initial architecture displays low stability towards dehydration and transforms rapidly into a second crystal phase corresponding to the partially dehydrated derivative, as evidenced by a remarkable modification in the diffraction pattern at temperatures just above $30{ }^{\circ} \mathrm{C}$. This derivative is fully formed at $50{ }^{\circ} \mathrm{C}$ and its pattern remains unmodified well beyond the complete evacuation of the water molecules up to $c a 110^{\circ} \mathrm{C}$, above which temperature it undergoes further gradual and subtle variations, leading to a third pattern corresponding to a final anhydrous phase that remains stable before undergoing progressive amorphization in the $190-230{ }^{\circ} \mathrm{C}$ range. These two transformations proceed with the crystals retaining their integrity, which allowed for the structures of both the dehydrated intermediate and the anhydrous phase to be determined from single-crystal X-ray diffraction experiments on crystals of the parent compound heated to 60 and $120{ }^{\circ} \mathrm{C}$, respectively, before performing the full data collection at $-173{ }^{\circ} \mathrm{C}$.

The partially dehydrated intermediate also crystallizes in the triclinic space group $P \overline{1}$ with the $b$ dimension and the unitcell volume nearly doubled due to a reduction of symmetry elements in the crystal. The asymmetric unit thus contains two crystallographically independent $\left[\mathrm{W}_{7} \mathrm{O}_{24}\right]^{6-}$ anions, eight halves of eight centrosymmetric $\{\mathrm{Cu}(\text { cyclam })\}^{2+}$ moieties, another two $\{\mathrm{Cu}(\text { cyclam })\}^{2+}$ moieties in general positions and 24 water molecules of hydration. Partial dehydration generates two crystallographically independent rhomb-like grids in the $a c$ plane because the POM units in alternate layers

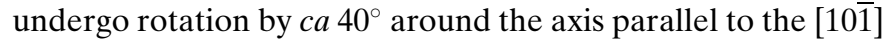


direction, while those in the remaining sheets remain nearly unaltered upon the SCSC transition. Moreover, the hybrid layers also undergo slippage by $(+0.5)$ and $(-0.25)$ along the crystallographic $a$ and $c$ axes, respectively, as indicated by the variations in the unit-cell angles $\alpha$ and $\gamma$. Such an intralamellar rearrangement of clusters and layer slippage not only induce the symmetry breaking that leads to the differentiation of hybrid grids, but also force all the interlamellar $\{\mathrm{Cu}(\text { cyclam })\}^{2+}$ moieties to adopt an elongated square-pyramidal coordination geometry due to the cleavage of one of the axial $\mathrm{Cu}-\mathrm{O}_{\mathrm{POM}}$ bonds, and those moieties belonging to the sheets affected by the POM rotation to migrate in its grafting site with a consequent bond rupture-formation process. Therefore, the interlamellar moieties lose their character as linkers to become decorating antenna units upon thermal evacuation of guest water molecules, and the dimensionality of the hybrid architecture lowers from the original three-dimensional covalent framework in the parent phase to a layered system in the partially dehydrated intermediate. The stacking of hybrid layers along the crystallographic $b$ axis becomes more compact as the interlamellar $\mathrm{Cu} \cdots \mathrm{Cu}$ distance shortens from ca 11.6 to $10.1 \AA$, but the framework still retains its porous nature because the superimposed cavities of both crystallographically independent sheets remain virtually identical in terms of size and shape. However, the two-dimensional porous network in the parent compound transforms into a system of parallel individual channels with a shorter cross section of $c a$ $9.8 \times 8.8 \AA$ (shortest internuclear distances between opposite $\mathrm{N}$ atoms) in the partially dehydrated phase due to their interconnection being disrupted along the [100] direction, in such a way that the solvent-accessible space hosting the remaining guest water molecules decreases to $22 \%$ of the unitcell volume (Fig. 10).

For the final anhydrous phase, the crystal lattice and space group become monoclinic $P 2_{1} / a$, with two crystallographically independent $\left[\mathrm{W}_{7} \mathrm{O}_{24}\right]^{6-}$ anions and eight $\{\mathrm{Cu}(\text { cyclam })\}^{2+}$ moieties (of which four are located on centres of inversion) in the asymmetric unit. Full dehydration induces the hybrid sheets in the $a c$ plane to become crystallographically equivalent again owing to further intralamellar rotation of the remaining POM units. However, additional distortions consisting of the intralamellar tilting of some of the $\{\mathrm{Cu}(\mathrm{cy}-$ clam) $\}^{2+}$ linkers result in the crystallographic differentiation of $\left[\mathrm{W}_{7} \mathrm{O}_{24}\right]^{6-}$ anions within the hybrid grids, with the rows of alternating POM units and metal-organic linkers along the [001] direction going from a linear to a zigzag conformation, and in the consequent formation of two different types of rhombic-like grid voids with cross sections of $10.0 \times 9.1$ and $9.2 \times 8.6 \AA$ (shortest internuclear distances between opposite $\mathrm{N}$ atoms). Focusing on the interlamellar region, half of the square-pyramidal metal-organic units that were decorating the hybrid layers in the partially dehydrated intermediate become square-planar charge-compensating subunits in the anhydrous phase due to the disruption of the apical $\mathrm{Cu}-$ $\mathrm{O}_{\mathrm{POM}}$ bond as a result of the intralamellar POM rotation. Both charge-compensating and antenna $\{\mathrm{Cu}(\text { cyclam })\}^{2+}$ interlamellar moieties act as cementing agents in the stacking of hybrid grids along the crystallographic $b$ axis through a dense scheme of $X-\mathrm{H} \cdots \mathrm{O}_{\mathrm{POM}}(X=\mathrm{N}, \mathrm{C})$ contacts that closely resembles that described for the decavanadate-based supramolecular framework in $\S 2.2$. This stacking, with analogous voids superimposed on each other, generates a porous system with two types of parallel guest-free channels of slightly different shapes that consist of a succession of wide cavities connected through narrow necks and contain solventaccessible void spaces accounting for 12 and $10 \%$ of the unitcell volume, respectively (Fig. 10). This guest-free activated phase is operative for the sorption of small gas molecules, such as $\mathrm{N}_{2}$ and $\mathrm{CO}_{2}$, with relative selectivity for the latter ( $c a 1.7$ molecules of $\mathrm{N}_{2}$ per POM unit versus 2.6 molecules of $\mathrm{CO}_{2}$ at 1 bar). The uptake of such molecules proceeds via type I isotherms characteristic of microporous materials and the BET surface area calculated from experimental data $\left(62.6 \mathrm{~m}^{2} \mathrm{~g}^{-1}\right)$ was found to be comparable to those of the ionic microporous crystalline materials described in $\$ 2.1$. The fact that the thermal evacuation of water molecules in this system proceeds via SCSC transformations permitted the determination of a precise structural model for the activated anhydrous phase in order to perform computational calculations that indicated the existence of narrow necks in the micropores as the key fact limiting the uptake of $\mathrm{N}_{2}$ over $\mathrm{CO}_{2}$.

According to thermogravimetric and powder X-ray diffraction monitoring on the reversibility of these two sequential SCSC transformations, the final anhydrous phase rapidly transforms back into the partially dehydrated derivative, which in turn constitutes a stable intermediate that cannot fully rehydrate into the parent compound. Crystalline samples of the anhydrous phase exposed to ambient moisture for one day readily captured 24 water molecules per two POM units and afforded a diffraction pattern consistent with that of the intermediate derivative. In contrast, neither the thermogravimetric dehydration curve nor the diffraction pattern appeared to undergo any noticeable modification when such samples were further exposed to ambient moisture for one month or immersed in distilled water for one week. These SCSC transitions are accompanied by solvatochromism, as crystalline samples of the parent compound adopt different colours for each of the phases produced by transformations. The original pink colour of the parent crystals darkens and acquires a pale-red tone when the compound transforms into the stable partially dehydrated intermediate, and becomes burgundy red when the anhydrous phase is formed. This chromism was attributed to the modifications from octahedral to square-pyramidal and then to square-planar that the coordination geometries of the interlamellar $\mathrm{Cu}^{\mathrm{II}}$ atoms undergo with the two sequential SCSC transitions.

\subsection{Sequential transformations in a metamorphic inorganic} framework

A purely inorganic extended framework, namely $\mathrm{Li}_{9} \mathrm{~K}_{7} \mathrm{Co}_{10^{-}}$ $\left[\left(\mathrm{WO}_{2}\right)\left(\mathrm{H}_{2} \mathrm{P}_{8} \mathrm{~W}_{48} \mathrm{O}_{184}\right)\right] \cdot 132 \mathrm{H}_{2} \mathrm{O}$, has been reported recently to display intriguing crystal dynamics triggered by a number of external stimuli (Zhan et al., 2017). This compound can 
undergo as many as eleven SCSC transformations that proceed through eight different metastable crystal phases in response to dehydration-rehydration processes, as well as to post-synthetic modification through the sorption of different molecules in the vapour phase $\left(\mathrm{NH}_{3}, \mathrm{MeOH}\right)$. This section will only comment on the former transformations.
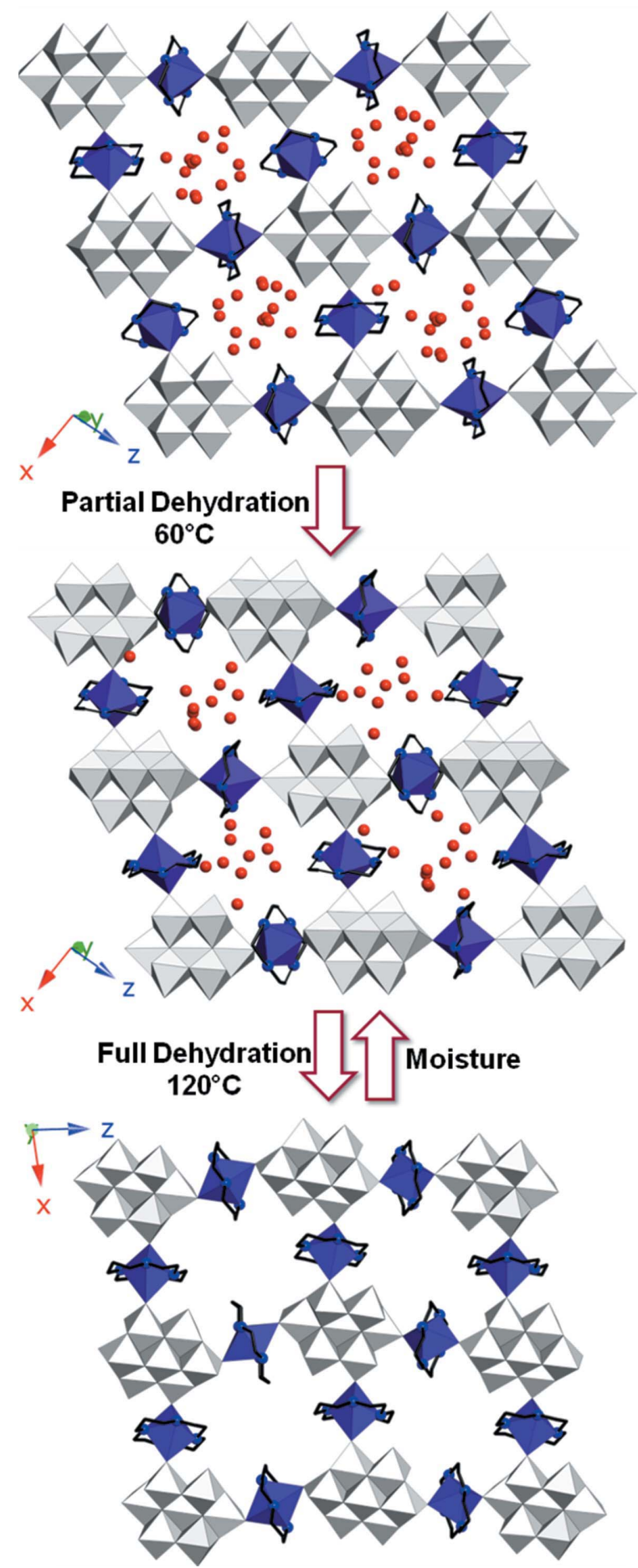

The parent compound crystallizes in the triclinic space group $P \overline{1}$ and the asymmetric unit contains one-half of the well-known crown-shaped $\left[\mathrm{P}_{8} \mathrm{~W}_{48} \mathrm{O}_{184}\right]^{10-}$ anion, with one additional $\left\{\mathrm{WO}_{2}\right\}$ group hosted in the central cavity, and five $\mathrm{Co}^{\text {II }}$ centres (of which three are disordered over five crystallographic positions) besides a number of severely disordered

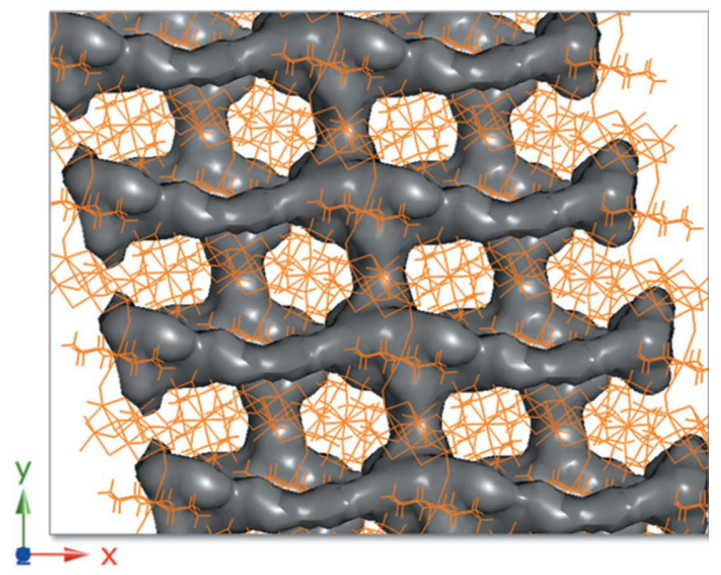

$\mathrm{W} \odot \mathrm{Cu} \odot \mathrm{N} \odot \mathrm{Ow}$
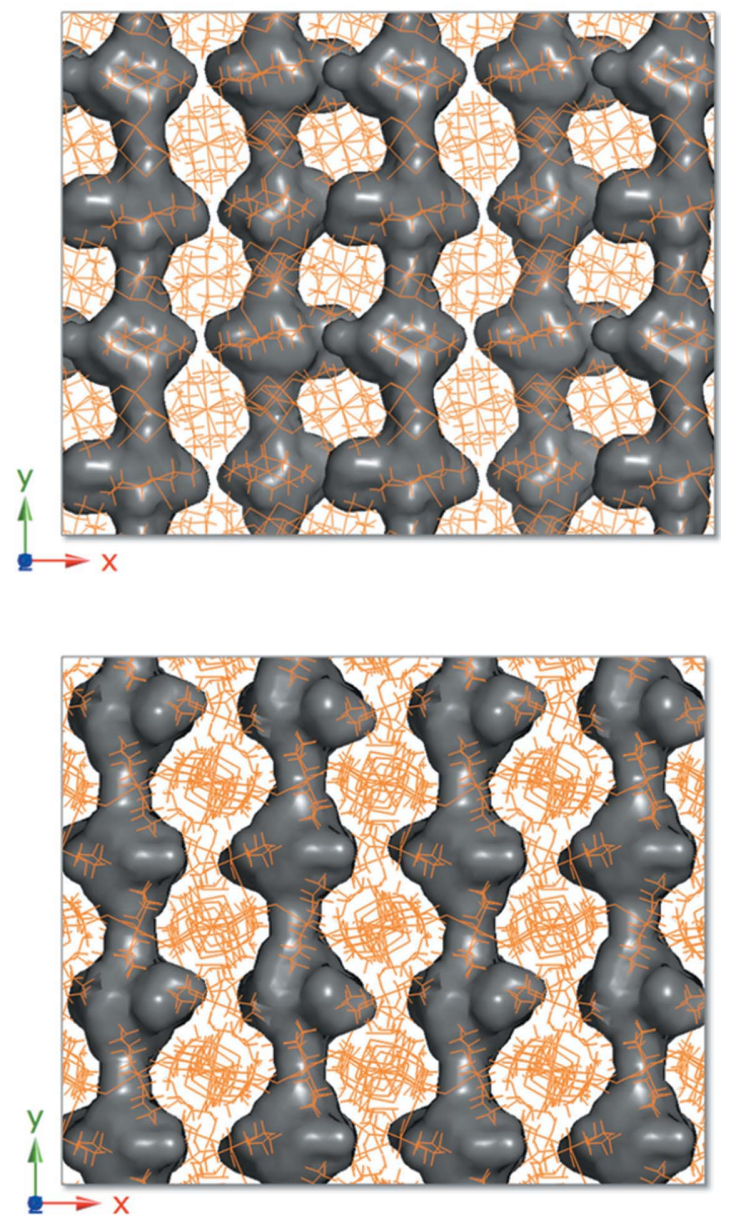

Figure 10

Comparison between hybrid rhombic-like grids projected on the crystallographic $a c$ plane ( $\mathrm{H}$ atoms have been omitted for clarity) and solvent-accessible spaces viewed along the crystallographic $c$ axis for $\left[\{\mathrm{Cu}(\text { cyclam })\}_{3}\left(\mathrm{~W}_{7} \mathrm{O}_{24}\right)\right] \cdot 15.5 \mathrm{H}_{2} \mathrm{O}$, its $\left[\{\mathrm{Cu}(\mathrm{cyclam})\}_{3}\left(\mathrm{~W}_{7} \mathrm{O}_{24}\right)\right] \cdot 12 \mathrm{H}_{2} \mathrm{O}$ partially dehydrated intermediate form, and the $[\mathrm{Cu}(\text { cyclam })]_{0.5}\left[\{\mathrm{Cu}(\text { cyclam })\}_{2.5}\left(\mathrm{~W}_{7} \mathrm{O}_{24}\right)\right]$ anhydrous phase. 
alkali cations and water molecules. The structure displays onedimensional covalent assemblies in which adjacent POM clusters are linked by three octahedral $\mathrm{Co}^{\mathrm{II}}$ centres along the crystallographic $b$ axis. Dehydration of this compound at $80^{\circ} \mathrm{C}$ under vacuum leads to the $\mathrm{Li}_{9} \mathrm{~K}_{7} \mathrm{Co}_{10}\left[\left(\mathrm{WO}_{2}\right)\left(\mathrm{H}_{2} \mathrm{P}_{8} \mathrm{~W}_{48} \mathrm{O}_{184}\right)\right]$-$74 \mathrm{H}_{2} \mathrm{O}$ phase via an SCSC transformation that involves remarkable contraction of the unit-cell volume from 7040 to $4870 \AA^{3}$ (which is consistent with the release of 58 water molecules considering $40 \AA^{3}$ per molecule) and a colour change from red to dark purple. The packing of neighbouring $\mathrm{POM} / \mathrm{Co}^{\mathrm{II}}$ chains in the structure of the partially dehydrated derivative becomes substantially more compact as a result of the release of a significant number of interstitial water molecules, which allows for a number of new $\mathrm{Co}-\mathrm{O}-\mathrm{W}$ linkages to be formed along the [100] direction, resulting in a twodimensional columnar architecture. When crystals of the partially dehydrated derivative are exposed to ambient moisture, a stable partially rehydrated $\mathrm{Li}_{9} \mathrm{~K}_{7} \mathrm{Co}_{10}\left[\left(\mathrm{WO}_{2}\right)\right.$ $\left.\left(\mathrm{H}_{2} \mathrm{P}_{8} \mathrm{~W}_{48} \mathrm{O}_{184}\right)\right] \cdot 95 \mathrm{H}_{2} \mathrm{O}$ phase is formed through an additional SCSC transition with associated solvatochromism from dark purple to pink-purple. Single-crystal X-ray diffraction experiments reveal the preservation of the two-dimensional columnar arrangement in the resulting crystals, with slight variations in the connectivity between chains. Full rehydration has not been demonstrated for this system, but a fourth distinct crystalline phase is obtained when crystals of either the partially dehydrated or rehydrated derivatives are stored for two weeks under a humid atmosphere. The structure of this compound, namely $\mathrm{Li}_{9} \mathrm{~K}_{7} \mathrm{Co}_{10}\left[\left(\mathrm{WO}_{2}\right)\left(\mathrm{H}_{2} \mathrm{P}_{8} \mathrm{~W}_{48} \mathrm{O}_{184}\right)\right] \cdot 125 \mathrm{H}_{2} \mathrm{O}$, closely resembles that found for the parent compound upon rupture of the $\mathrm{Co}-\mathrm{O}-\mathrm{W}$ bonds responsible for the columnar arrangements in the partially dehydrated and rehydrated derivatives, but with adjacent $\mathrm{POM} / \mathrm{Co}^{\mathrm{II}}$ chains connected through additional side-to-side $\mathrm{Co}-\mathrm{O}-\mathrm{W}$ linkages into twodimensional covalent lattices parallel to the $b c$ plane.

\section{Conclusions}

The still relatively low number of literature reports on SCSC transformations triggered by dehydration in POM-based compounds has been compiled and reviewed in this article. The fact that such a phenomenon has already been found for a range of compositionally (from purely inorganic compounds to organic salts and hybrid POM/metal-organic materials) and structurally (from molecular species to ionic crystals and extended covalent frameworks) different systems, as well as for several external triggering stimuli beyond dehydration (temperature, light, redox processes, post-synthetic modifications), appears to indicate that crystal-phase transitions in either polymorphic, robust or dynamic materials might be a relatively common feature worth analyzing for POM-based structures, rather than an exceptional phenomenon.

\section{Acknowledgements}

The following institutions are acknowledged for support: Universidad Pública de Navarra, Obra Social la Caixa and
Fundación Caja Navarra (contract to SR in the framework of the program 'Captación del Talento'); Universidad del País Vasco UPV/EHU (grants PPG17/37 and GIU17/050); Ministerio de Economía, Industria y Competitividad (grant MAT2017-89553P).

\section{References}

Alvarez, S., Avnir, D., Llunell, M. \& Pinsky, M. (2002). New J. Chem. 26, 996-1009.

Aromí, G., Beavers, C. M., Sánchez Costa, J., Craig, G. A., Mínguez Espallargas, G., Orera, A. \& Roubeau, O. (2016). Chem. Sci. 7, 2907-2915.

Avdeeva, V. V., Buzin, M. I., Malinina, E. A., Kuznetsov, N. T. \& Vologzhanina, A. V. (2015). CrystEngComm, 17, 8870-8875.

Barats-Damatov, D., Shimon, L. J. V., Feldman, Y., Bendikov, T. \& Neumann, R. (2015). Inorg. Chem. 54, 628-634.

Centore, R., Capitolino, V., Cerciello, F., Tuzi, A., Borbone, F., Carella, A. \& Roviello, R. (2015). CrystEngComm, 17, 8864-8869.

Chen, C. L., Goforth, A. M., Smith, M. D., Su, C. Y. \& zur Loye, H. C. (2005). Angew. Chem. Int. Ed. 44, 6673-6677.

Coronado, E., Giménez-Marqués, M., Espallargas, G. M. \& Brammer, L. (2012). Nat. Commun. 3, 828.

Coronado, E. \& Mínguez Espallargas, G. (2013). Chem. Soc. Rev. 42, $1525-1539$.

Dissem, N., Artetxe, B., San Felices, L., Lezama, L., Haddad, A. \& Gutiérrez-Zorrilla, J. M. (2018). Crystals, 8, 20.

Don, A. \& Weakley, T. J. R. (1981). Acta Cryst. B37, 451-453.

Eguchi, R., Uchida, S. \& Mizuno, N. (2012). Angew. Chem. Int. Ed. 51, 1635-1639.

Fernández de Luis, R., Urtiaga, M. K., Mesa, J. L., de Segura, J. O. G., Rojo, T. \& Arriortua, M. I. (2011). CrystEngComm, 13, 6488-6498.

Finke, R. G., Droege, M. W. \& Domaille, P. (1987). Inorg. Chem. 26, 3886-3896.

Friššić, T. \& MacGillivray, L. R. (2005). Z. Kristallogr. 220, 351-363.

Groom, C. R., Bruno, I. J., Lightfoot, M. P. \& Ward, S. C. (2016). Acta Cryst. B72, 171-179.

Hagihara, R., Harada, N., Karasawa, S. \& Koga, N. (2015). CrystEngComm, 17, 8825-8834.

Halasz, I. (2010). Cryst. Growth Des. 10, 2817-2823.

Hao, Z. M. \& Zhang, X. M. (2011). Dalton Trans. 40, 2092-2098.

Iturrospe, A., Artetxe, B., Reinoso, S., San Felices, L., Vitoria, P., Lezama, L. \& Gutiérrez-Zorrilla, J. M. (2013). Inorg. Chem. 52, 3084-3093.

Iturrospe, A., San Felices, L., Reinoso, S., Artetxe, B., Lezama, L. \& Gutiérrez-Zorrilla, J. M. (2014). Cryst. Growth Des. 14, 2318-2328.

Kawahara, R., Uchida, S. \& Mizuno, N. (2014). Inorg. Chem. 53, 3655-3661.

Kawamoto, R., Uchida, S. \& Mizuno, N. (2005). J. Am. Chem. Soc. 127, 10560-10567.

Ke, S. Y. \& Wang, C. C. (2015). CrystEngComm, 17, 8776-8785.

Khorasani, S., Botes, D. S., Fernandes, M. A. \& Levendis, D. C. (2015). CrystEngComm, 17, 8933-8945.

Kikukawa, Y., Yamaguchi, K. \& Mizuno, N. (2010a). Angew. Chem. Int. Ed. 49, 6096-6100.

Kikukawa, Y., Yamaguchi, K. \& Mizuno, N. (2010b). Inorg. Chem. 49, 8194-8196.

Kuriyama, Y., Kikukawa, Y., Suzuki, K., Yamaguchi, K. \& Mizuno, N. (2016). Chem. Eur. J. 22, 3962-3966.

Lee, J. H., Kim, T. K., Suh, M. P. \& Moon, H. R. (2015). CrystEngComm, 17, 8807-8811.

Lesbani, A., Kawamoto, R., Uchida, S. \& Mizuno, N. (2008). Inorg. Chem. 47, 3349-3357.

Li, Q. Q., Ren, C. Y., Huang, Y. Y., Li, J. L., Liu, P., Liu, B., Liu, Y. \& Wang, Y. Y. (2015). Chem. Eur. J. 21, 4703-4711.

Manna, B., Desai, A. V., Kumar, N., Karmakar, A. \& Ghosh, S. K. (2015). CrystEngComm, 17, 8796-8800. 
Martín-Caballero, J., Artetxe, B., Reinoso, S., San Felices, L., Castillo, O., Beobide, G., Vilas, J. L. \& Gutiérrez-Zorrilla, J. M. (2017). Chem. Eur. J. 23, 14962-14974.

Martín-Caballero, J., San José Wéry, A., Reinoso, S., Artetxe, B., San Felices, L., El Bakkali, B., Trautwein, G., Alcañiz-Monge, J., Vilas, J. L. \& Gutiérrez-Zorrilla, J. M. (2016). Inorg. Chem. 55, 4970-4979.

Mizuno, N., Uchida, S. \& Uehara, K. (2009). Pure Appl. Chem. 81, 2369-2376.

Mouchaham, G., Gualino, M., Roques, N., Duhayon, C., Brandès, S. \& Sutter, J. P. (2015). CrystEngComm, 17, 8906-8914.

Neogi, S., Sen, S. \& Bharadwaj, P. K. (2014). Encyclopedia of Inorganic and Bioinorganic Chemistry, pp. 1-50. Chichester: John Wiley \& Sons.

Pache, A., Reinoso, S., San Felices, L., Iturrospe, A., Lezama, L. \& Gutiérrez-Zorrilla, J. M. (2015). Inorganics, 3, 194-218.

Pope, M. T. \& Scully, T. F. (1975). Inorg. Chem. 14, 953-954.

Reinoso, S., Artetxe, B., San Felices, L. \& Gutiérrez-Zorrilla, J. M. (2016). Polyoxometalates: Properties, Structure and Synthesis, edited by A. P. Roberts, pp. 143-212. Hauppauge, NY: Nova Science Publishers.

Reinoso, S., Dickman, M. H., Praetorius, A. \& Kortz, U. (2008). Acta Cryst. E64, m614-m615.

Ren, H. Y., Yao, R. X. \& Zhang, X. M. (2015). Inorg. Chem. 54, 63126318.

Ritchie, C., Streb, C., Thiel, J., Mitchell, S. G., Miras, H. N., Long, D. L., Boyd, T., Peacock, R. D., McGlone, T. \& Cronin, L. (2008). Angew. Chem. Int. Ed. 47, 6881-6884.

Sergienko, V. S., Korai-Koshits, M. A. \& Yurchenko, E. N. (1980). Zh. Strukt. Khim. 21, 111-125.

Shi, L. X., Zhao, W. F., Xu, X., Tang, J. \& Wu, C. D. (2011). Inorg. Chem. 50, 12387-12389.

Tagami, H., Uchida, S. \& Mizuno, N. (2009). Angew. Chem. Int. Ed. 48, 6160-6164.

Tahier, T. \& Oliver, C. L. (2015). CrystEngComm, 17, 8946-8956.

Takahashi, H. \& Tamura, R. (2015). CrystEngComm, 17, 8888-8896.
Thiel, J., Ritchie, C., Miras, H. N., Streb, C., Mitchell, S. G., Boyd, T., Corella Ochoa, M. N., Rosnes, M. H., McIver, J., Long, D. L. \& Cronin, L. (2010). Angew. Chem. Int. Ed. 49, 6984-6988.

Thiel, J., Ritchie, C., Streb, C., Long, D. L. \& Cronin, L. (2009). J. Am. Chem. Soc. 131, 4180-4181.

Uchida, S., Eguchi, R. \& Mizuno, N. (2010). Angew. Chem. Int. Ed. 49, 9930-9934.

Uchida, S., Eguchi, R., Nakamura, S., Ogasawara, Y., Kurosawa, N. \& Mizuno, N. (2012). Chem. Mater. 24, 325-330.

Uchida, S., Kawahara, R., Ogasawara, Y. \& Mizuno, N. (2013a). Dalton Trans. 42, 16209-16215.

Uchida, S., Kawamoto, R., Akatsuka, T., Hikichi, S. \& Mizuno, N. (2005). Chem. Mater. 17, 1367-1375.

Uchida, S., Kawamoto, R. \& Mizuno, N. (2006). Inorg. Chem. 45, 5136-5144.

Uchida, S. \& Mizuno, N. (2004). J. Am. Chem. Soc. 126, 1602-1603.

Uchida, S. \& Mizuno, N. (2007). Coord. Chem. Rev. 251, 25372546.

Uchida, S., Mizuno, K., Kawahara, R., Takahashi, E. \& Mizuno, N. (2014). Chem. Lett. 43, 1192-1194.

Uchida, S., Takahashi, E. \& Mizuno, N. (2013b). Inorg. Chem. 52, 9320-9326.

Uehara, K. \& Mizuno, N. (2011). J. Am. Chem. Soc. 133, 1622-1625.

Wéry, A. S. J., Gutiérrez-Zorrilla, J. M., Luque, A., Ugalde, M. \& Román, P. (1996). Chem. Mater. 8, 408-413.

Zakharov, B. A., Marchuk, A. S. \& Boldyreva, E. V. (2015). CrystEngComm, 17, 8812-8816.

Zhan, C., Cameron, J. M., Gabb, D., Boyd, T., Winter, R. S., VilàNadal, L., Mitchell, S. G., Glatzel, S., Breternitz, J., Gregory, D. H., Long, D.-L., Macdonell, A. \& Cronin, L. (2017). Nat. Commun. 8, 14185.

Zhang, L. Z., Gu, W., Dong, Z., Liu, X. \& Li, B. (2008a). CrystEngComm, 10, 1318-1320.

Zhang, L. Z., Gu, W., Liu, X., Dong, Z. \& Li, B. (2008b). CrystEngComm, 10, 652-654. 